\title{
INCIDENCIA DEL ESTATUS MIGRATORIO EN EL INGRESO $Y$ BRECHAS SALARIALES DE GÉNERO DE MIGRANTES COSTARRICENSES EN EL NORESTE DE ESTADOS UNIDOS
}

\author{
EFFECT OF THE MIGRATORY STATUS IN THE INCOME AND GENDER WAGE \\ GAP OF COSTA RICAN IMMIGRANTS LIVING IN THE NORTHEAST OF THE UNI- \\ TED STATES
}

Jose Arroyo-González ${ }^{1}$

\begin{abstract}
RESUMEN
El presente es el primer estudio sobre el ingreso económico de migrantes costarricenses residentes en el noreste de Estados Unidos. Las estimaciones fueron posibles gracias a un cuestionario aplicado a la población durante el primer semestre de 2018. El estudio muestra que la mayoría de estas personas vive en Nueva Jersey; además, un $32 \%$ se encuentra en condición migratoria irregular, y casi el $90 \%$ tiene empleo, aunque las mujeres tienen un $11,29 \%$ menos probabilidad de trabajar que un hombre. Además, se determina que la tenencia de permiso de trabajo no impacta en el ingreso de la mayoría de las personas y que más bien, podría suponer hasta un $29 \%$ menos ingreso para los hombres que trabajan en ocupaciones elementales. También, el ser mujer disminuye hasta en un $23,8 \%$ el ingreso de las personas y que hay evidencia estadística para afirmar que existe un componente discriminatorio en detrimento de las mujeres.
\end{abstract}

PALABRAS CLAVE: MIGRACIÓN, MIGRANTE IRREGULAR, BRECHAS DE GÉNERO, ESTATUS MIGRATORIO

CLASIFICACIÓN JEL: J310, J610; J710

\section{ABSTRACT}

This is the first study regarding the income of Costa Rican immigrants in the northeast of the United States. The estimations were possible after the submission of a questionnaire during the first semester of 2018 . The study shows that the majority of the population lives in New Jersey; that $32 \%$ of the population lives under an irregular migratory status; that 
almost $90 \%$ of the population has a job, but women are $11.29 \%$ less likely to be employed than men. The study shows that the legal authorization for work in the U.S. does not impact the income of the majority of the population, moreover, it would represent a 29\% decrease in the income of men who work in basic-skilled occupations. Also, showed that women receive $23.8 \%$ less income than men and there is statistical evidence that supports the existence of a discriminatory component against women.

KEY WORDS: IMMIGRATION, UNAUTHORIZED IMMIGRANT, GENDER WAGE GAP, MIGRATORY STATUS

JEL: CLASSIFICATION: J310, J610; J710

\section{I.INTRODUCCION}

En La presente investigación analiza el ingreso económico de la población costarricense radicada en el noreste de Estados Unidos desde una perspectiva de su estatus migratorio y las brechas de ingreso según el género. Para tales efectos, se estiman ecuaciones de ingreso de Mincer (1974), a partir de un cuestionario aplicado desde el Consulado de Costa Rica en Nueva York y haciendo un análisis de brechas de ingreso con la metodología descrita por Oaxaca y Ransom (1994).

La justificación para realizar el estudio radica en la importancia de visibilizar las circunstancias sociales de la población migrante costarricense, cuyas problemáticas sociales van desde estar indocumentada, sufrir pobreza, violencia, abandono, abuso y adicción a las drogas, indigencia, accidentes laborales, incapacidad financiera para la repatriación de cuerpos y muchos otros ejemplos. La compleja situación se agrava con los limitados recursos del Consulado y la inexistente información, bases de datos o estudios sobre esta población. Por lo anterior, es necesario crear una base de datos con información sobre esta población, analizar su dinámica migratoria $y$ visibilizar la atención que requiere este grupo poblacional en el exterior por parte del Estado costarricense.

La colonia costarricense en Estados Unidos es, por amplio margen, la más grande en el mundo. Normalmente hay extensos estudios sobre la población migrante radicada en Costa Rica, pero no así estudios sobre costarricenses en otras partes del mundo. Según el padrón electoral del Tribunal Supremo de Elecciones (TSE) enviado directamente al Consulado, al 3 de octubre de 2017, había 8674 costarricenses empadronados para votar en Nueva York para las elecciones presidenciales del 2018, siendo el Consulado costarricense más populoso del mundo. Este Consulado abarca el noreste de Estados Unidos, específicamente los Estados de Pensilvania, Nueva Jersey, Nueva York, Connecticut, Rhode Island, Massachusetts, Nuevo Hampshire, Vermont y Maine.

Existe información imprecisa respecto al número total de costarricenses viviendo en Estados Unidos: se estima que esta oscila entre 85.924 (Organización Internacional para las Migraciones, 2015) y 154.784 personas (U.S. Census Bureau, 2018). Las cifras muestran, además, que el peso relativo de la población costarricense en relación con el total de población de hispanos es muy bajo: de apenas un 0,25\% del total (U.S. Census Bureau, 2018). Como se observa, es difícil contar con una estimación confiable de la cantidad de costarricenses viviendo en Estados Unidos. Resulta más difícil aún, determinar cuántos son residentes legales. Según el American Community Survey 2018 (U.S. Census Bureau, 2018) el 52,48\% nació fuera de Estados Unidos, es decir que corresponde a migrantes, pero no se tienen datos específicos sobre la población migrante en condición irregular.

Las limitaciones para estimar el número de costarricenses en el exterior, así como contar con un perfil poblacional son evidentes. Aún más es la carencia de información específica sobre la situación económica, familiar, de estatus migratorio, del ingreso, de ocupaciones, de niveles académicos, poblaciones desfavorecidas y otras variables claves que permitan diseñar políticas migratorias acordes. El Censo de Población de Estados Unidos recolecta información valiosa sobre 
el nivel socioeconómico de las personas migrantes; sin embargo, no hace diferenciación entre la población residente autorizada y no autorizada.

Se entiende como personas residentes no autorizadas a "todas aquellas personas nacidas fuera de Estados Unidos que no son residentes legales" (United States Department of Homeland Security, 2018)2. La gran mayoría de esta población se encuentra en esta categoría, ya sea porque entraron a Estados Unidos sin una debida inspección por un puesto migratorio establecido por Customs and Border Protection (CBP) o porque les fue concedida una permanencia legal temporal en Estados Unidos y se quedaron más del tiempo estipulado. Para enero de 2015, el Department of Homeland Security (2018) estimó 12 millones de personas residentes no autorizadas en Estados Unidos. Los cálculos se realizan mediante operaciones aritméticas, en las cuales se sustrae de la población nacida fuera de Estados Unidos, todas aquellas personas que son residentes legales. Además, todas las personas que entraron a Estados Unidos antes de 1980 se asumen que son residentes legales. La diferencia obtenida se entiende como migración no autorizada.

La población residente migrante no autorizada se ha convertido en un tema de política económica prioritario en Estados Unidos. La actual administración ha mostrado un endurecimiento de la política migratoria, sobre todo para migrantes no autorizados. Entre otras cosas, ha querido incorporar en el Censo 2020 una pregunta sobre la tenencia de la nacionalidad estadounidense, pero a raíz de fundadas preocupaciones desde organizaciones de la sociedad civil y a una orden de la Corte Suprema de Justicia, la Administración dio marcha atrás en incluirla (Min Kim, Bahrampour y Wagner, 2019).

Ser migrante no autorizado en Estados Unidos vuelve el proceso de regularización más complicado. Los migrantes no autorizados, sin importar cuanto tiempo han residido en ese país, deben obtener primero su estatus como residente permanente $y$, posteriormente, si lo desean, la nacionalidad estadounidense; la cual brinda protección ante un eventual proceso de deportación, concede derechos políticos (de elegir y ser electos políticamente), brinda acceso a beneficios sociales y a becas, da el derecho a concursar por ciertos empleos específicos y da acceso a algunos subsidios puntuales exclusivos para ciudadanos estadounidenses (Aptekar, 2015). No obstante, los inmigrantes que menos obtienen la nacionalidad provienen de países latinoamericanos, particularmente de México, Guatemala y El Salvador (Aptekar, 2015).

La población migrante no autorizada presenta mayores niveles de pobreza que la autorizada (Capps et al., 2013). En la primera, se estima que el 32\% de las personas adultas y el $51 \%$ de la población infantil viven por debajo de la línea de pobreza federal, el $71 \%$ no cuentan con ningún tipo de seguro, y solo el 30\% de los mayores de 19 años habla inglés (Capps et al., 2013). Además, los hijos de padres migrantes no autorizados presentan menores tasas de matrícula en prescolar, mayores niveles de pobreza, una menor probabilidad de salir de la pobreza y un menor manejo del inglés en edades tempranas que los hijos de migrantes regulares y estadounidenses nativos (Capps, Fix, Zong, 2016). Un 43\% de los hijos de padres no autorizados que hablan inglés presentan aislamiento idiomático en sus hogares (Capps, Fix, Zong, 2016).

De acuerdo con Borjas (2017), para toda la población migrante en Estados Unidos, el salario por hora no ajustado de los migrantes no autorizados es de aproximadamente un $40 \%$ menos con relación a los estadounidenses nativos. Sin embargo, ajustando el ingreso con diversas variables socioeconómicas observables (edad, educación y estado de residencia), esa diferencia se reduce a la mitad. Un hombre migrante no autorizado tiene un $92 \%$ de probabilidad de estar empleado en un año calendario, en contraste con un 85 y $81 \%$ de probabilidad que tiene un migrante autorizado $y$ un nativo estadounidense respectivamente. Sin embargo, esta mayor probabilidad de empleo no necesariamente está asociada a mejores calidades de trabajo. Para las mujeres, la probabilidad 
va en la otra dirección: la mujer migrante no autorizada tiene un $61 \%$ de probabilidad de estar empleada, en contraste con un 64 y $72 \%$ de la migrante autorizada y la nativa estadounidense respectivamente. Borjas (2017) también encuentra que el ingreso de los migrantes no autorizados se mantiene estancado a lo largo de los años (en contraste con los migrantes autorizados y los nativos).

Asimismo, en general, la brecha salarial entre migrantes autorizados y no autorizados se ha reducido en Estados Unidos (Borjas, 2017). En 2005, un migrante no autorizado ganaba 10\% menos que un migrante autorizado por el hecho de ser no autorizado (componente no explicado o discriminatorio); para 2014 esa brecha se redujo a 4\%. Borjas no da una posible explicación para este fenómeno, pero como bien lo observa Guilford (2017), la brecha empieza a reducirse desde 2008, coincidiendo con el inicio de la Administración Obama, la crisis financiera mundial, la desaceleración de las nuevas llegadas de migrantes a Estados Unidos y del regreso voluntario de muchos migrantes a sus países de origen. Lo anterior, aunado a que la oferta de trabajo de la población migrante no autorizada es muy inelástica (Guilford, 2017).

Para el caso costarricense en particular, hay información muy escueta. Hay estudios sobre disparidad de ingresos de migrantes en general y sobre todo de México y del resto de Centroamérica. Caicedo (2015) encuentra una serie de disparidades de los migrantes provenientes de Latinoamérica y los nativos estadounidenses, pero entre los países analizados no se encuentra Costa Rica. Por otro lado, Lara (2017) hace una comparación del ingreso de los migrantes, pero únicamente mexicanos. Ante la inexistencia de estudios para costarricenses ${ }^{3}$ y tomando en cuenta que no hay información específica sobre los migrantes no autorizados, se crea y aplica una encuesta para realizar la presente investigación, la primera en su tipo para el caso costarricense.

Según el American Community Survey (U.S. Census Bureau, 2018), si se compara, a grandes rasgos, la población migrante proveniente de la región centroamericana y México, se tiene que quienes dijeron ser costarricenses tienen un ingreso anual por hogar mayor que el resto, mayor proporción de trabajadores en ocupaciones más calificadas y una menor proporción de población en pobreza (considérese la tabla 1). Sin embargo, esta es la población total de personas que dijeron ser o tener ascendencia de cierto país, no necesariamente migrantes. A manera de ilustración, según el U.S. Census Bureau (2018), la concentración de costarricenses (nativos y migrantes) en Nueva Jersey, California y Florida es de 25.026, 22.793 y 22.753 personas respectivamente, información que no se ajusta a lo reportado por los consulados. Además, no se hace una diferenciación entre migrantes autorizados y no autorizados, que es el tema que nos ocupa en la presente investigación.

2 Existen estudios sobre migrantes costarricenses en Estados Unidos, pero desde un punto de vista sociológico, no así, para determinar el ingreso de las personas. Kordick-Rothe (2007), por ejemplo, describe que muchos migrantes salen de la Zona de lo Santos, donde se observan problemas psicológico-sociales por la división de las familias. Caamaño (2010), por su parte, estudia también el fenómeno migratorio en regiones expulsoras como la Zona de los Santos y Pérez Zeledón y su conexión con el Estado de Nueva Jersey, donde se identifica un fenómeno social de "trasnacionalismo" donde comunidades mantienen prácticas sociales o tradiciones del país de origen en el país de destino. 


\section{CUADRO 1}

INDICADORES SELECCIONADOS PARA PERSONAS IDENTIFICADAS COMO MEXICANAS O DE CENTROAMÉRICA VIVIENDO EN EE. UU.

\begin{tabular}{|c|c|c|c|c|c|c|c|}
\hline Variable & MEX & GUA & HON & ESV & NIC & PAN & CRC \\
\hline Población total & 36.986 .661 & 1.524 .743 & 963.930 & 2.306 .774 & 434.000 & 206.219 & 154.784 \\
\hline $\begin{array}{l}\text { Porcentaje de población } \\
\text { masculina }\end{array}$ & 51 & 54,70 & 50,90 & 51,10 & 46,90 & 43,80 & 47,40 \\
\hline $\begin{array}{l}\text { Porcentaje de la población } \\
\text { nacida fuera de Estados } \\
\text { Unidos }\end{array}$ & 30,14 . & 60,28 & 61,28 & 56,95 & 56,07 & 39,09 & 52,49 \\
\hline $\begin{array}{l}\text { Porcentaje de ocupados } \\
\text { en puestos de gerencia, } \\
\text { profesionales y artes }\end{array}$ & 19,60 & 12,70 & 13,50 & 14,50 & 25,30 & 37,50 & 38,70 \\
\hline $\begin{array}{l}\text { Ingreso anual medio en } \\
\text { dólares de un hogar }\end{array}$ & 51.204 & 48.509 & 43.197 & 53.684 & 60.268 & 56.955 & 65.912 \\
\hline $\begin{array}{l}\text { Porcentaje de hogares } \\
\text { viviendo por debajo de la } \\
\text { línea de pobreza }\end{array}$ & 17,10 & 22,40 & 23,50 & 15,20 & 12,20 & 7,90 & 8,30 \\
\hline
\end{tabular}

Fuente: Elaboración propia con información del American Community Survey (U.S. Census Bureau, 2018).

Nota: Países por siglas respectivamente: México, Guatemala, Honduras, El Salvador, Nicaragua, Panamá y Costa Rica.

Aunque el Consulado en Nueva York no diferencia entre migrantes costarricenses autorizados y no autorizados en Estados Unidos, se sabe que esta población existe. Según consulta directa hecha el 18 de octubre de 2017 al Pew Research Center, para 2015, se calculaba la población migrante costarricense no autorizada en treinta mil personas, para todo el territorio de Estados Unidos; pero no se tienen datos sobre su concentración. Es por lo anterior que, en este estudio, se recopila información concerniente a la jurisdicción del Consulado de Costa Rica en Nueva York, con respecto al número relativo de costarricenses no autorizados y cuánto incide esta condición sobre su ingreso.

En relación con las brechas de género, tampoco hay información para el caso costarricense, pero, en general, las mujeres latinas en Estados Unidos ganan 54 dólares por cada 100 que gana un hombre blanco (National Partnership for Women and Families, 2017) y esta brecha se observa también dentro de una misma ocupación, es decir, remuneración diferenciada por un mismo trabajo (National Women's Law Center, 2017a). Estas diferencias salariales, además, varían de acuerdo con el Estado, siendo Nueva Jersey el más desigual, donde la mujer latina gana 42,9 dólares por cada 100 que gana un hombre blanco (National Women's Law Center, 2017b). Este dato es de especial importancia para la comunidad costarricense que, como veremos más adelante, está concentrada en ese Estado.

Es importante que las autoridades y los propulsores de políticas económicas y migratorias costarricenses tengan conocimiento de la realidad de las condiciones de ingreso de las personas migrantes costarricenses. Por lo tanto, con este estudio, se recolecta información útil que ayude a determinar si hay alguna relación entre la tenencia de autorización para trabajar y el ingreso. También se ahonda en determinar si existe una brecha en el ingreso en relación con el género. La esperanza es que tales hallazgos puedan ser analizados, que generen insumos a las instituciones costarricenses pertinentes y que permitan diseñar una política pública migratoria, más informada y humana, apegada a las necesidades de la población costarricense en el exterior. 


\section{METODOLOGÍA Y DATOS}

Con el fin de recopilar la información para elaborar este estudio, se diseñó un cuestionario para identificar las características personales y familiares de los migrantes costarricenses, su domicilio, procedencia en Costa Rica, educación, trabajo e ingresos y aspectos propios de la forma en que migraron a los Estados Unidos. Dicho cuestionario se aplicó entre el 13 de febrero y el 20 de mayo de 2018, mayoritariamente, a través del envío directo por correo electrónico a costarricenses migrantes radicados en Estados Unidos, que se encontraban empadronados en el Consulado General de Costa Rica en Nueva York.

Con el visto bueno del Consulado, mediante la autorización directa del Cónsul General y con el compromiso de compartir los resultados con el Consulado, se facilitaron los correos electrónicos de las personas empadronadas en dicha oficina consular. El cuestionario enfatiza que se trata de respuestas confidenciales y además anónimas. Este instrumento contó con autorización institucional de la Universidad de Costa Rica, oficio Nro. VI-6668-CEC-0056-2018 del 5 de octubre de 2018.

El cuestionario incluyó preguntas de verificación, las cuales permitieron corroborar que la persona estaba contestando consecuentemente. Por ejemplo, si la persona dice ser costarricense, se le pregunta el primer número de su cédula; o al contestar la cantidad de años de escolaridad, se le pregunta más adelante el último año de estudio aprobado. De igual forma, se hace con la variable de experiencia laboral, que fue construida tomando en cuenta períodos de desempleo o inactividad y la variable de permanencia en Estados Unidos, a partir de los meses o años que la persona ha estado en el país, descontando los períodos de intermitencia. Estas preguntas son importantes porque el Consulado mantiene una lista de usuarios que lo visitan, costarricenses o no, que hacen uso de sus servicios, por lo que es necesario garantizar la participación apropiada de estas personas. Se enviaron un total de 14769 invitaciones a los correos electrónicos, de las cuales 2281 rebotaron por ser direcciones inválidas o en desuso. Se recopilaron un total de 1406 respuestas completas.

Luego de contar con las respuestas completas, fue necesario empezar con un proceso de depuración de los datos. Muchas observaciones estaban completas, pero sus respuestas no se ajustaban a lo que se preguntaba. Por ejemplo, aquellas personas que no comprendieron la pregunta y respondieron tener más experiencia laboral que años cumplidos o un ingreso familiar menor al ingreso personal. Finalmente, luego de toda la depuración cuyo proceso tardó varios meses, en total, 513 personas respondieron de manera completa el cuestionario; de ellas 452 reportaron estar empleadas. Además, hay un compromiso previo con 407 personas encuestadas que dejaron de manera voluntaria un correo electrónico para el envío de los hallazgos de la presente investigación.

Como se mencionó, había 8.674 costarricenses empadronados para votar en 2018, en el Consulado en Nueva York. Así las cosas, el número mínimo de observaciones requeridas para generar resultados significativos a un $95 \%$ de confianza era de 368 personas, por lo que el número de observaciones recolectadas (513) resulta suficiente. No obstante, como los datos son recolectados tomando como base la visitación de costarricenses al Consulado, no podría afirmarse fehacientemente, que la muestra representa en todos sus extremos a la población en general. Por tanto, los resultados deben interpretarse con base a esta muestra analizada y no a la población total.

Los costarricenses acuden al Consulado a realizar trámites sin importar su situación migratoria en Estados Unidos. Uno de esos trámites es la solicitud de cédula de identidad, documento necesario para adquirir un pasaporte costarricense. En Estados Unidos, el pasaporte funge como un documento de identidad válido, utilizado en forma generalizada por todos los migrantes. Por ejemplo, con el pasaporte, los migrantes indocumentados pueden identificarse ante autoridades, casarse, visitar familiares en hospitales o entrar a establecimientos exclusivos para mayores de edad, $y$ dependiendo del Estado de residencia, pueden abrir cuentas bancarias y aplicar por licencias de conducir. También es un documento requerido por los migrantes autorizados, por ejemplo, para 
solicitar un número de seguro social, pagar impuestos, obtener licencias de conducir, viajar y para solicitar cualquier otro documento de identidad extendido por los Estados Unidos.

Según la ley costarricense, la cédula de identidad extendida por el Registro Civil es el documento requerido para tener acceso a cualquier servicio prestado por el Consulado, incluyendo la tramitación del pasaporte, constituyendo un servicio de primera necesidad para la población. Cuando la persona aplica por la cédula en el Consulado (o en cualquier otra oficina del Registro Civil o consulado en el mundo) y aporta un domicilio en la jurisdicción del Consulado en Nueva York, queda automáticamente empadronada para votar en esa oficina. Es por esa misma razón que se utilizó como referencia el número de empadronados aportado por el TSE, ya que el proceso de empadronamiento exige un trámite formal de obtención de cédula o de cambio de domicilio electoral. Así las cosas, el Consulado es la oficina que brinda la fotografía más fidedigna de la población costarricense en esta región de Estados Unidos. Quedan por fuera aquellas personas que viviendo en la jurisdicción del Consulado y de acuerdo con sus posibilidades de viajar, decidan hacer sus trámites en Costa Rica y votar en suelo nacional.

\section{Variables utilizadas}

Las variables utilizadas en el estudio se subdividen en tres categorías. La primera es de índole migratorio, cuyas variables son: la red migratoria, cantidad de años como migrante en Estados Unidos y la tenencia o no de autorización para trabajar, expedida por el US. Citizens and Immigration Services. La red migratoria se define como la red de amigos, familiares o círculo social común que colaboran en el establecimiento de la persona migrante en los Estados Unidos. Lo anterior, porque tal y como lo explican Boswell (2002), Massey y García-España (1987) y Caamaño (2010) para el caso costarricense, hay evidencia de que las interacciones sociales entre potenciales migrantes con personas en comunidades receptoras coadyuvan a la perpetuación de la migración. Estas redes o interacciones sociales son de conocidos, amigos y familiares, normalmente connacionales, que ayudan a otra persona a asentarse en el lugar de destino y se pensaría que son beneficiosas en el ingreso de las personas. Por otro lado, los años de permanencia en Estados Unidos se toman en cuenta bajo el supuesto de que las personas con más tiempo en ese país tendrían una relativa estabilidad laboral y financiera. Finalmente, la tenencia de permiso de trabajo se incluye para estudiar su efecto en el ingreso de las personas, sobre todo en tiempos donde la discusión sobre la migración ilegal es tema de conversaciones políticas al más alto nivel en los Estados Unidos.

La segunda categoría de variables incorporadas son las de capital humano (Becker, 1962; Mincer, 1974): la escolaridad, el nivel de inglés y la experiencia. La tercera categoría, por su parte, son aquellas características personales observables, como si la persona es jefe de hogar, si es mujer, si vive en pareja, la ocupación y si tiene personas a su cuido. A continuación, en la tabla 2, se detallan las variables correspondientes. 


\title{
CUADRO 2 \\ DESCRIPCIÓN DE VARIABLES UTILIZADAS EN LA ESTIMACIÓN DE MODELOS DE INGRESO Y BRECHAS SALARIALES DE GÉNERO
}

\begin{abstract}
Variable Descripción

Red migratoria Variable migratoria dicotómica que toma el valor 1 si la persona recibió ayuda de familiares, amigos y conocidos para instalarse o encontrar empleo en EE. UU. al momento de migrar. Toma el valor 0 si no recibió ayuda.

Permiso de Variable migratoria dicotómica que toma el valor 1 si la persona cuenta con una autorización para trabajo laborar en Estados Unidos, extendida por la institución correspondiente. Toma el valor 0 si no cuenta con el permiso.

Permanencia Variable migratoria construida a partir de la cantidad de años que la persona ha vivido en EE. UU. en EE. UU. A aquellos que han vivido interrumpidamente, se le toma en cuenta únicamente el tiempo efectivo residiendo en EE. UU.

Años de Variable de capital humano construida a partir de la cantidad de años de educación formal que la escolaridad persona tiene, independientemente si estudió en Costa Rica o en Estados Unidos.

Experiencia Variable de capital humano que corresponde a la cantidad de años que la persona ha trabajado durante su vida. Se le preguntan períodos de desempleo o inactividad y la variable fue construida a partir de esa información.

Inglés Variable de capital humano dicotómica que toma el valor 1 si la persona considera que tiene un buen nivel de inglés, 0 si considera que su inglés no es bueno. Es una variable de autopercepción, puesto que no fue aplicado ningún diagnóstico.

Ocupación Variable de característica personal dicotómica construida tomando en cuenta las competencias detalladas en la clasificación de ocupaciones del Instituto Nacional de Estadística y Censos (INEC). Las competencias son definidas como "la capacitación necesaria para llevar a cabo eficazmente las tareas y cometidos correspondientes a un determinado empleo" (pp. 12. INEC, 2014). La variable dicotómica toma el valor 1 para las competencias en las dos primeras categorías que son más sofisticadas y 0 para las categorías 3 y 4 que son más elementales.

Mujer Variable de característica personal dicotómica que toma valor 1 si la persona se auto percibe como mujer y 0 si se auto percibe como hombre. Al tiempo de la encuesta, el Tribunal Supremo de Elecciones solo consideraba estas dos opciones.

Pareja Variable de característica personal dicotómica. Toma el valor de 1 si persona vive en pareja y 0 si no.
\end{abstract}

Personas a Variable de característica personal dicotómica que toma valor 1 si la persona tiene a su cuido personas cargo menores a 6 años, adultos mayores o personas con discapacidad. Toma el valor 0 en caso negativo.

Jefe de hogar Variable de característica personal dicotómica que toma el valor 1 si la persona considera que tiene la jefatura del hogar, es decir, que si considera que su ingreso significa el mayor aporte económico relativo al hogar. Toma el valor 0 en caso contrario.

Salario por Logaritmo natural del salario actual, anual y antes de impuestos, dividido por el número de semanas y hora horas laboradas a la semana.

Fuente: Elaboración propia 


\section{Ecuación de empleo}

Con el objetivo de determinar la probabilidad de empleo, se estima una ecuación probabilística (probit) que se plantea de la siguiente forma:

$$
P_{i}=P(Y=1 \mid X)=P\left(I_{i}^{*} \leq I_{i}\right)=P\left(Z_{i} \leq \beta X\right)=F(B X)=\frac{1}{\sqrt{2 \pi}} \int_{-\infty}^{B X} e^{-z^{2} / 2} d z,
$$

donde la probabilidad de estar empleado es 1 cuando, dadas las características de cada persona, ese valor probabilístico excede el umbral $I_{\star}{ }_{\star}$, utilizando la distribución normal estándar. Dado lo anterior, es posible plantear el modelo de variable latente para determinar la probabilidad de que la persona esté empleada de la siguiente manera:

$$
P(\text { empleo }=1)=\alpha_{0}+\alpha_{1} \text { escolaridad }+\alpha_{2} \text { Experiencia }+\alpha_{3} \text { Experiencia }^{2}+\sum_{4}^{n} \alpha_{i} * \text { var.interés; }
$$

donde la probabilidad de estar empleado es la variable dependiente. Este cálculo incluye toda la muestra, es decir quienes están y no están ocupados, con el fin de determinar las relaciones de probabilidad del empleo. El modelo incluye las variables usuales de la ecuación de Mincer (1974), que son escolaridad y experiencia laboral. Además, incluye la variable "inglés" como propia de capital humano. Las variables de interés se refieren a las variables migratorias o de índole personal que podrían afectar la probabilidad de que la persona labore. Esas variables son: permiso de trabajo, red migratoria, si el individuo tiene personas a cargo, si vive en pareja, si es mujer y si es jefe de hogar.

Además, estos cálculos de probabilidad se hicieron de manera separada para hombres y mujeres, con el objetivo de determinar si una corrección muestral de Heckman (1979) era necesaria, procedimiento que se explicará más adelante.

\section{Planteamiento de la ecuación de ingreso}

El salario de mujeres y hombres será estimado mediante ecuaciones de Mincer (1974) donde la variable dependiente es el logaritmo del salario por hora y las variables independientes son el resto de las variables contenidas en el cuadro 2. Para efectos metodológicos, se considera que las variables de interés propias de la presente investigación son: la red migratoria, permanencia en EE.UU. y el permiso de trabajo. Las variables propias del modelo de capital humano son: la escolaridad, la experiencia laboral, la experiencia laboral al cuadrado y el nivel de inglés. Las variables de control son: ser mujer, si la persona vive en pareja, si tiene personas a cargo, si es jefe de hogar y la ocupación. La ecuación de Mincer (1974) se plantea de la siguiente manera:

$$
\operatorname{In}(W)=\beta_{0}+\beta_{1} \text { escolaridad }+\beta_{2} \text { experiencia }+\beta_{3} \text { experiencia }{ }^{2}+\sum_{4}^{n} \beta_{i}^{*} \text { var.interés, }
$$

\section{Cálculo de la brecha salarial y componente discriminatorio}

Para tales efectos se utiliza el modelo de Oaxaca y Ransom (1994). Se corren dos ecuaciones por el método de mínimos cuadrados ordinarios para ambos grupos (hombres y mujeres), y se obtienen los valores promedio, de la siguiente manera:

$$
\begin{aligned}
& \operatorname{In}\left(\tilde{W}_{M}\right)=\bar{X}^{{ }^{\prime}}{ }_{M} \hat{\beta}_{M} \\
& \operatorname{In}\left(\tilde{W}_{H}\right)=\bar{X}{ }_{H}{ }_{H} \hat{\beta}_{H}
\end{aligned}
$$


donde $\tilde{W}$,es el promedio geométrico de los salarios, $\left(\bar{X}^{\prime}\right)$ es el vector de características promedio y $\beta$ es el vector de coeficientes estimados (los subíndices M y $\mathrm{H}$ se refieren a las observaciones para mujeres y hombres respectivamente).

El diferencial salarial está dado por:

$$
\begin{gathered}
\operatorname{In}\left(G_{H M}+1\right)=\operatorname{In}\left(\tilde{W}_{H}\right)-\operatorname{In}\left(\tilde{W}_{M}\right) \\
\operatorname{In}\left(G_{H M}+1\right)=\bar{X}^{\prime}{ }_{H} \hat{\beta}_{H}-\bar{X}^{\prime}{ }_{M} \hat{\beta}_{M} \\
\operatorname{In}\left(G_{H M}+1\right)=\bar{X}^{\prime}{ }_{H}\left(\hat{\beta}_{H}-\beta^{*}\right)+\bar{X}^{\prime}{ }_{M}\left(\beta^{*}-\hat{\beta}_{M}\right)+\left(\bar{X}_{H}-\bar{X}_{M}\right)^{\prime} \beta^{*},
\end{gathered}
$$

(A)

(B)

(C)

(D)

donde A) es el diferencial bruto en los salarios observados entre hombres y mujeres, B) es el beneficio o favorecimiento que tienen los hombres, C) es el perjuicio salarial de las mujeres a razón de la discriminación y D) es el componente del diferencial salarial explicado por la diferencia en productividades. El vector $\beta^{*}$ corresponde a la estructura salarial que hubiera en caso de no existir discriminación, calculando los estimadores mediante una regresión agrupada de hombres y mujeres. Según Oaxaca y Ransom (1994) se define de la siguiente forma:

$$
\beta^{*}=\Omega \hat{\beta}_{H}+(I-\Omega) \hat{\beta}_{M}
$$

donde I es la matriz identidad $y \Omega$ se define como:

$$
\Omega=\left(X^{\prime}{ }_{H} X_{H}+X^{\prime}{ }_{M} X_{M}\right)^{-1}\left(X^{\prime}{ }_{H} X_{H}\right)
$$

En este tipo de estimaciones es común que exista un sesgo de selección muestral, cuando individuos por sus características personales deciden no trabajar. Según Heckman (1979) se puede hacer una corrección muestral, tomando en consideración la probabilidad de que esa persona, dadas sus características personales, decida no trabajar y mantenerse inactiva. Una primera etapa es calcular el estimador $\hat{\lambda}$ razón inversa de Mills) en un modelo probit de empleo. Este cálculo se realiza corriendo dos regresiones probit para hombres y para mujeres, cuya variable dependiente es la probabilidad de estar ocupado y las variables independientes son sus características personales. Una vez obtenido $\hat{\lambda}$, este se incluye en la regresión salarial como una variable independiente más de la siguiente forma:

$$
\begin{aligned}
& \operatorname{In}\left(\tilde{W}_{M}\right)=\bar{X}{ }_{M}{ } \hat{\beta}_{M}+\hat{\lambda} \sigma \\
& \operatorname{In}\left(\tilde{W}_{H}\right)=\bar{X}{ }_{H}{ }_{H} \hat{\beta}_{H}+\hat{\lambda} \sigma
\end{aligned}
$$

donde $\Omega$ es la covarianza entre las ecuaciones de salarios y las ecuaciones de la probabilidad de inactividad del modelo probit. Si $\hat{\lambda}$ es estadísticamente significativo, la corrección de Heckman (1979) es requerida y relevante para esta selección muestral.

\section{Estadísticas descriptivas de la muestra}

Con respecto a la población en estudio y tomando como referencia la muestra de 513 personas, se procede a presentar las estadísticas descriptivas de la muestra en el cuadro 3. 


\section{Estadísticas descriptivas de la muestra}

Con respecto a la población en estudio y tomando como referencia la muestra de 513 personas, se procede a presentar las estadísticas descriptivas de la muestra en la tabla 3.

TABLA 3

\section{RESUMEN DE ESTADÍSTICAS DESCRIPTIVAS PARA HOMBRES Y MUJERES}

\begin{tabular}{|c|c|c|c|}
\hline Variable & Total & Hombres & Mujeres \\
\hline Observaciones & 513 & 272 & 241 \\
\hline \multicolumn{4}{|l|}{ Distribución porcentual de personas: } \\
\hline Procedentes del Gran Área Metropolitana (GAM) & $56,93 \%$ & $52,57 \%$ & $63,48 \%$ \\
\hline $\begin{array}{l}\text { Procedentes de los cantones colindantes de Pérez } \\
\text { Zeledón y Buenos Aires de Puntarenas }\end{array}$ & $17,34 \%$ & $20,6 \%$ & $12,45 \%$ \\
\hline $\begin{array}{l}\text { Procedentes de la Zona de los Santos (cantones de } \\
\text { Tarrazú, Dota y León Cortés). }\end{array}$ & $6,4 \%$ & $7,35 \%$ & $4,98 \%$ \\
\hline Procedentes de otras partes de Costa Rica & $19,33 \%$ & $19,48 \%$ & $19,09 \%$ \\
\hline $\begin{array}{l}\text { Porcentaje de personas que comprende y habla el idioma } \\
\text { inglés. }\end{array}$ & $82,22 \%$ & $84,2 \%$ & $79,2 \%$ \\
\hline $\begin{array}{l}\text { Porcentaje de personas que cuenta con empleo } \\
\text { actualmente. }\end{array}$ & $89,23 \%$ & $95,6 \%$ & $79,6 \%$ \\
\hline $\begin{array}{l}\text { Promedio de horas que la persona trabaja durante la } \\
\text { semana en su empleo actual. }\end{array}$ & 45,6 & 49,7 & 38,3 \\
\hline $\begin{array}{l}\text { Porcentaje de personas que considera su empleo como } \\
\text { permanente. }\end{array}$ & $78,68 \%$ & $87 \%$ & $66 \%$ \\
\hline Promedio del ingreso anual en dólares estadounidenses. & $\$ 61.419,57$ & $\$ 69.553$ & $\$ 46.758$ \\
\hline $\begin{array}{l}\text { Media de ingreso por hora de personas en ocupaciones } \\
\text { más sofisticadas }\end{array}$ & $\$ 35,4$ & $\$ 36,54$ & $\$ 33,29$ \\
\hline $\begin{array}{l}\text { Media de ingreso por hora de personas en ocupaciones } \\
\text { más elementales }\end{array}$ & $\$ 24,04$ & $\$ 25,47$ & $\$ 21,47$ \\
\hline Porcentaje con permiso de trabajo & $68,14 \%$ & $66,5 \%$ & $70,5 \%$ \\
\hline $\begin{array}{l}\text { Porcentaje de personas que recibió algún tipo de } \\
\text { asistencia al llegar a EE.UU. (red migratoria). }\end{array}$ & $80,67 \%$ & $79,4 \%$ & $82,6 \%$ \\
\hline Edad promedio en años cumplidos. & 39,29 & 40 & 38,3 \\
\hline $\begin{array}{l}\text { Porcentaje de personas que dijo ser el jefe de hogar } \\
\text { (fuente principal de ingresos del hogar). }\end{array}$ & $71,16 \%$ & $83,4 \%$ & $52,7 \%$ \\
\hline Porcentaje de personas que vive en pareja. & $67,75 \%$ & $70,6 \%$ & $63,4 \%$ \\
\hline $\begin{array}{l}\text { Porcentaje de personas que tiene alguna persona a su } \\
\text { cuido (personas adultas mayores, discapacitadas). }\end{array}$ & $6,07 \%$ & $5 \%$ & $7,4 \%$ \\
\hline Permanencia estimada en EE.UU. en años. & 16,60 & 17,2 & 15,6 \\
\hline Promedio de años de escolaridad. & 13,29 & 12,8 & 14 \\
\hline Promedio de la experiencia laboral en años. & 21,37 & 23,4 & 18,2 \\
\hline Porcentaje de personas con hijos menores a 6 años. & $22,75 \%$ & $22,43 \%$ & $23,24 \%$ \\
\hline
\end{tabular}

Fuente: : Elaboración propia 
Cabe destacar que, de acuerdo con el padrón electoral del TSE., hay un 39,9\% de población femenina. Así las cosas, todas las estadísticas anteriores fueron calculadas con pesos estadísticos, ya que las mujeres se encuentran levemente sobre representadas en la muestra (46,9\%). Con esto, se pretende corregir la sobrerrepresentación femenina en la muestra, aunque los resultados obtenidos se interpreten únicamente en referencia a la muestra y no la población.

Sobre la procedencia de las personas costarricenses, la muestra confirma la percepción de que un porcentaje importante proviene de los cantones de Pérez Zeledón, Buenos Aires y de la Zona de los Santos (Tarrazú, Dota y León Cortés); información que concuerda con los datos del INEC (2014). Además, la proporción de hombres emigrantes de estos cantones es mayor que las mujeres. La gran mayoría de las mujeres salen del Gran Área Metropolitana (GAM).

Una enorme mayoría de las personas contestó tener un buen nivel de inglés. Sobre el particular, es preciso indicar que se trata de una autopercepción, no se aplicó ninguna prueba diagnóstica para corroborar estos resultados. Es destacable, además, el alto porcentaje de empleabilidad que tienen los migrantes, sobre todo los hombres, donde un 95,6\% dijo contar con empleo. La participación laboral femenina es también elevada, de casi un $80 \%$, situación que contrasta con el promedio de 50\% de participación laboral femenina en Costa Rica (Morales \& Segura, 2018). Lo anterior tiene sentido, en el entendido de que el objetivo principal de migrar a los Estados Unidos es la búsqueda de oportunidades de trabajo.

En general, los hombres tienen más experiencia laboral y más tiempo de permanencia en Estados Unidos; las mujeres tienen mayor escolaridad, pero menor ingreso por hora. Esta situación es similar a la que ocurre en Costa Rica, donde las mujeres tienen un mejor perfil educativo, pero esto no se traduce en oportunidades de empleo para las mujeres (Informe del Estado de la Nación, 2018). En promedio, las mujeres reportan 11 horas menos de trabajo a la semana, situación que repercute parcialmente en que reciban en promedio un $32.7 \%{ }^{4}$ menos remuneración que los hombres; resultados similares a los de Costa Rica, donde las mujeres reportan 10 horas menos de trabajo semanales (Solórzano, 2018). Tanto los hombres y las mujeres costarricenses trabajan más horas en los Estados Unidos que en Costa Rica, donde según la Encuesta Nacional de Hogares para el 2017, los hombres y mujeres trabajan 45 y 35 horas semanales respectivamente (Informe del Estado de la Nación, 2018).

En relación con las variables de interés para efectos migratorios, a saber: permanencia en EE. UU., permiso de trabajo y red migratoria; se hicieron pruebas t-estadísticas y arrojan que las diferencias entre hombres y mujeres no son significativas, se trata de poblaciones muy similares. Es necesario tomar en cuenta estos resultados más adelante debido a que las estimaciones de ingreso son similares para ambos grupos.

Haciendo un análisis más profundo de la información, lo primero que es necesario acotar es que la población de estudio meta es diversa y particular. No existe un único perfil poblacional y a grandes rasgos se pueden identificar dos grandes grupos. El primero son aquellas personas que emigraron desde Costa Rica por una buena oportunidad de empleo, estudio o capacitación técnica, que cuentan y siempre contaron con un estatus legal para laborar o estudiar en el país, que es más probable que salieran del GAM y se asentaran en los estados de Nueva York y Massachusetts y que se dedican en mayor proporción a ocupaciones más sofisticadas. El segundo grupo son aquellas personas que no contaban con estas oportunidades y decidieron salir de Costa Rica por necesidades socio económicas apremiantes, que vinieron con una visa de turismo y se quedan irregularmente más del tiempo reglamentado o que cruzaron la frontera ilegalmente por México, que es más probable que salieran de la Zona de los Santos y Pérez Zeledón y que se asentaran en el estado de Nueva Jersey, desempeñándose en ocupaciones más elementales.

$7 \quad$ Porcentaje que representa la diferencia en los ingresos de los hombres y las mujeres, dividido entre el ingreso de los hombres. 
Los dos perfiles mencionados quedan claramente representados en la categorización que se hizo de las ocupaciones. El grupo con ocupaciones más sofisticadas reporta mayores ingresos por hora promedio $(\$ 35,4)$, mayor proporción de personas con permiso de trabajo $(88,2 \%)$ y menor proporción de personas que recibieron ayuda de una red migratoria (75\%). En contraste, el grupo de ocupaciones más elementales tienen menores ingresos por hora promedio $(\$ 24)$, menos personas con autorización para laborar $(57,9 \%)$ y relativamente tuvieron más acceso a ayudas por medio de una red migratoria (85\%).

\section{GRÁFICO 1 \\ ÍNGRESO POR HORA PROMEDIO EN RELACIÓN CON LA REGIÓN DE PROCEDENCIA}

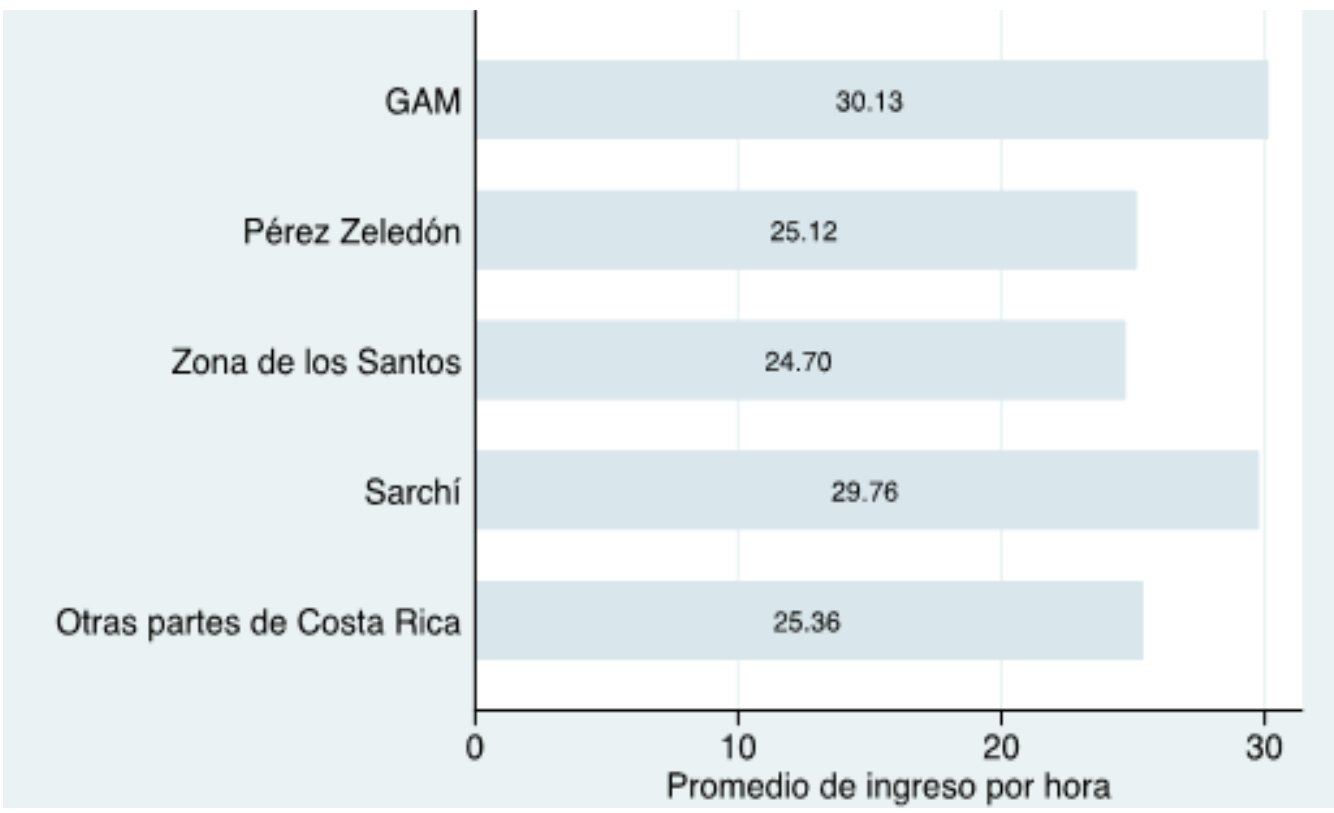

Fuente: : Elaboración propia

En el gráfico 1 se aprecia el ingreso por hora promedio en relación con la región de procedencia en Costa Rica. La mayoría de la población migrante es procedente del Gran Área Metropolitana y es también la región de origen cuyas personas reportan más ingreso. Quienes emigraron desde la Zona de los Santos y Pérez Zeledón, son los que reportan menos ingresos en EEUU. Sólo el $19.33 \%$ de los migrantes provienen del resto de cantones de Costa Rica. Tal y como se sugiere en la literatura (Kordick-Rothe, 2007 y Caamaño, 2010), la Zona de los Santos y Pérez Zeledón son regiones históricamente emisoras de migrantes hacia los Estados Unidos, información que ha sido corroborada por el INEC (2014). Relativamente más personas oriundas de estos cantones (31\%) se desempeñan en ocupaciones elementales que quienes provienen del resto del país. En contraparte, sólo el 13.7\% de los directores, gerentes, profesionales y técnicos provienen de esos cantones.

Por otro lado, $y$ consistentemente con estudios demográficos anteriores (INEC, 2014 y Caamaño, 2010), la mayoría de costarricenses (54.17\% de la muestra) se domicilia en el estado de Nueva Jersey. Además, el $62.8 \%$ de las personas que se dedican a labores más elementales y el 71.23\% de la población migratoria irregular viven en ese estado.

En cuanto a la escolaridad, la media de años de educación formal de la población es de 13.29 años con 12.77 años para los hombres y 14.07 para las mujeres. Los años de escolaridad fueron computados en una sola variable, ya que hay personas que tienen su último año de estudio en Costa 
Rica (60.9\% del total) y el resto con su último año de estudio en los Estados Unidos. Como dato importante tenemos que, relativamente más mujeres tienen su último año aprobado en los Estados Unidos (un 43.15\%), en relación con los hombres (36.4\%). Nueva Jersey es el estado donde las personas reportaron la menor cantidad de años de educación promedio (12.1 años) y Massachusetts el que reportó la mayor escolaridad (15.4 años).

\section{GRÁFICO 2 \\ DISTRIBUCIÓN DE OCUPACIONES SEGÚN EL INGRESO}

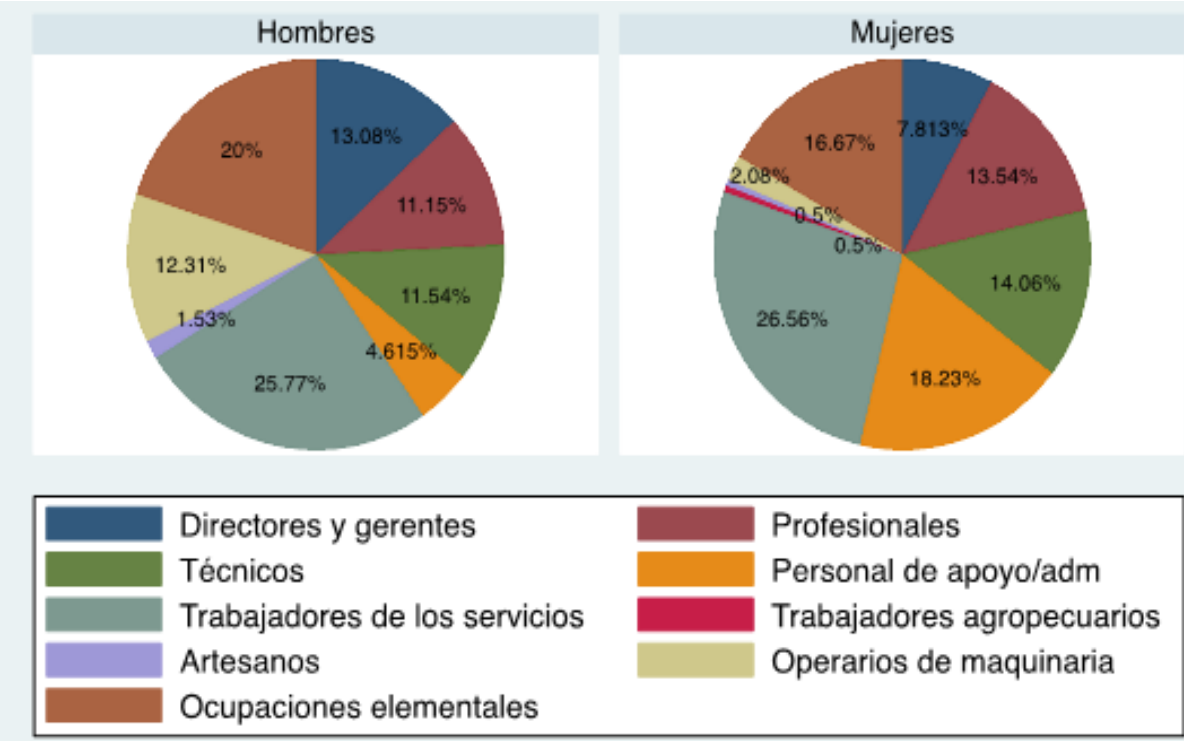

Fuente: Elaboración propia

Fuente: : Elaboración propia

Sobre las ocupaciones que desempeñan los costarricenses en el noreste de Estados Unidos, encontramos la distribución en el gráfico 2. Tanto para los hombres como para las mujeres, las ocupaciones más usuales se relacionan con la prestación de servicios, cuidados personales o servicios de protección. En esta categoría se incluye, por ejemplo, los vendedores en comercios, cocineros, cuido de niños o adultos mayores, estilistas, entre muchos otros. También hay diferencias importantes: las mujeres ocupan más puestos profesionales técnicos y administrativos; más hombres ocupan ocupaciones elementales $y$ operan maquinaria.

El ingreso por ocupaciones se presenta en el gráfico 3. En este gráfico se desagregan algunas ocupaciones elementales para efectos ilustrativos, como trabajadores del campo, peones y limpieza de casas, ya que son ocupaciones con muchas observaciones por sí mismas. 


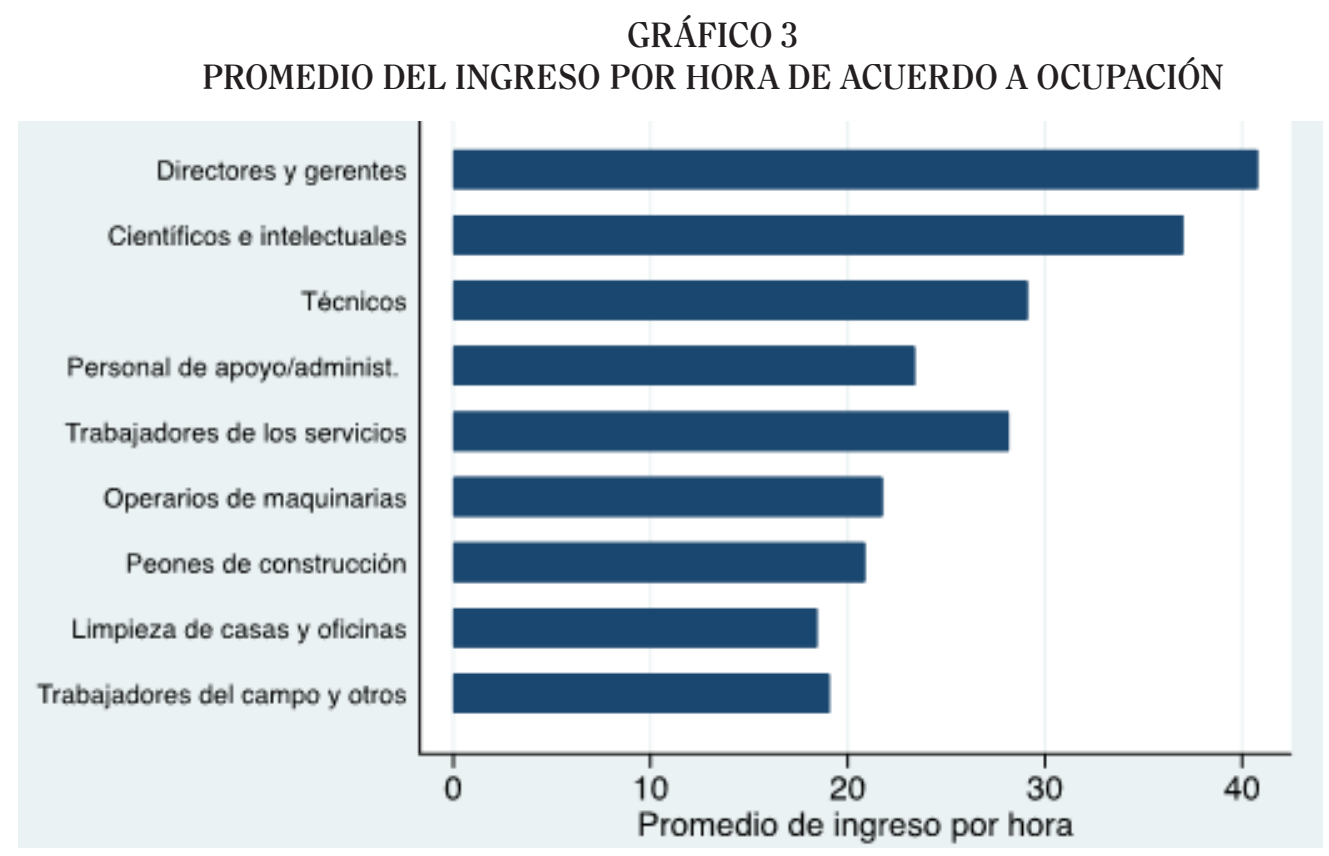

Fuente: : Elaboración propia

Tomando en cuenta la clasificación metodológica descrita en relación con las competencias para las ocupaciones, el grupo de ocupaciones altas están comprendidos por los directores y gerentes, profesionales científicos e intelectuales y los técnicos, quienes son los que también en el cuadro 4 reportan más ingreso. El resto de las ocupaciones reportan menos ingresos y son las personas que limpian casas u oficinas las que reportan menos ingreso, perjudicando especialmente a las mujeres, que corresponden al 85\% de las personas en este oficio. En general, como se vio en elcuadro 3, para las ocupaciones menos sofisticadas, las mujeres reportan menos ingresos que los hombres; $\$ 21,4$ y $\$ 25,4$ respectivamente.

A continuación, en el cuadro 3, se procede a separar el ingreso por hora de las ocupaciones.

\section{CUADRO 3 \\ RESUMEN DE ESTADÍSTICAS DESCRIPTIVAS PARA HOMBRES Y MUJERES}

\begin{tabular}{|c|c|c|c|c|}
\hline Variable & Total & Hombres & Mujeres & $\begin{array}{c}\text { Diferencial } \\
\text { hombres/mujeres }\end{array}$ \\
\hline Solo para directores y gerentes & 40,78 & 41,83 & 37,59 & $11,27 \%$ \\
\hline Solo para profesionales & 36,99 & 36,37 & 37,91 & $-4 \%$ \\
\hline Solo para técnicos & 29,10 & 30,68 & 26,84 & $14,3 \%$ \\
\hline $\begin{array}{l}\text { Total de ingreso promedio para ocupaciones } \\
\text { sofisticadas }\end{array}$ & 35,38 & 36,53 & 33,29 & $9,73 \%$ \\
\hline $\begin{array}{l}\text { Total ingreso promedio de ocupaciones } \\
\text { elementales }\end{array}$ & 24,04 & 25,47 & 21,47 & $18,63 \%$ \\
\hline
\end{tabular}

Fuente: : Elaboración propia 
Como se desprende del cuadro 4, a excepción de las personas que se desempeñan como profesionales científicos e intelectuales, los hombres ganan más que las mujeres. Aunque en este rubro, las mujeres ganan más (4\%), el diferencial salarial es menos importante comparándolo con las otras categorías. Los hombres ganan un $11.27 \%$ más salario por hora que las mujeres si son directores $y$ gerentes $y$ un $18,63 \%$ si laboran en ocupaciones elementales.

\section{GRÁFICO 4 \\ RAZONES PARA NO ESTAR EMPLEADO}

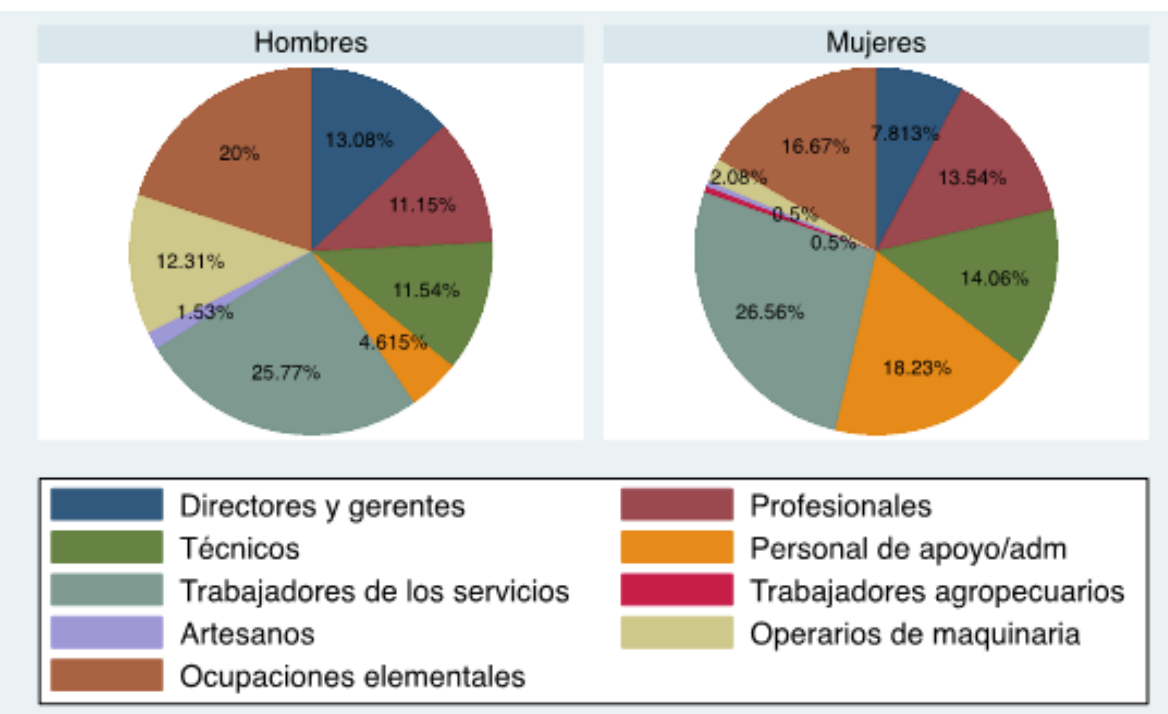

Fuente: : Elaboración propia

La inmensa mayoría de la población trabaja. Solamente el 10,77\% de la muestra no se encontraba trabajando al momento de contestar el cuestionario. El gráfico 4 muestra las razones por las cuales las personas adujeron no tener un empleo en ese momento. Las diferencias son importantes en relación con el género. Casi el 50\% de las mujeres dijo no trabajar por cuidar a niños. Para los hombres, las razones son más equilibradas, siendo el estudio y el desempleo (personas que han buscado trabajo activamente en las últimas 4 semanas y no han encontrado) las dos categorías más importantes.

Como se aprecia en el gráfico 4, solo el 16,67\% de los hombres y el 10,2\% de las mujeres que no tienen empleo atribuyeron a la no tenencia de permiso de trabajo como razón para no estar empleado. Aunque dichas apreciaciones no permiten inferir más allá en cuanto al impacto de la tenencia o no del permiso de trabajo, los datos sugieren que la no tenencia de permiso, en general, no representa un obstáculo para trabajar. Sobre este mismo tema, no se evidencia que el promedio de la tenencia varíe en relación con el género y perfil ocupacional; es decir, no hay evidencia estadística para rechazar la hipótesis de que estos grupos sean iguales o muy similares, lo anterior corroborado mediante las pruebas t-estadísticas respectivas (valor $\mathrm{t}$ de -0,012). 


\section{CUADRO 5 \\ DISTRIBUCIÓN PORCENTUAL DE PERSONAS CON PERMISO PARA LABORAR SEGÚN LA OCUPACIÓN Y EL SEXO}

\begin{tabular}{lrr}
\hline Variable & Hombres & Mujeres \\
\hline Porcentaje de directores y gerentes con permiso de trabajo & 88,24 & 80 \\
Porcentaje de profesionales con permiso de trabajo & 86,21 & 96,15 \\
Porcentaje de técnicos con permiso de trabajo & 90 & 85,71 \\
Porcentaje de ocupados en ocupaciones más elementales con permiso de trabajo & 55,09 & 62,9 \\
Porcentaje de personas sin trabajo que tienen permiso de trabajo & 58,33 & 65,3 \\
\hline
\end{tabular}

Fuente: : Elaboración propia

Una observación esperable del cuadro 5 es que la gran mayoría de los directores, profesionales y técnicos cuentan con permiso para trabajar. Sin embargo, una característica muy interesante es que, en promedio, más personas sin empleo tienen autorización para trabajar, comparado con aquellas que se desempeñan en ocupaciones más elementales. Además, las estadísticas descriptivas muestran que más personas sin empleo tienen más años de escolaridad (13,73 años) que quienes se dedican a ocupaciones básicas (11,73 años). En otras palabras, quienes no trabajan, por los motivos explicados más arriba, no lo hacen, aunque son más educados y cuentan con permiso para hacerlo, en contraste con aquellos que se dedican a actividades más elementales.

Lo anterior refuerza la hipótesis de que el permiso laboral no afecta en gran medida el acceso al trabajo en los Estados Unidos. Esto tiene sentido, en el entendido que, para una persona dedicada a ocupaciones elementales y que se encuentra en Estados Unidos, su razón principal para migrar y permanecer en este país es trabajar y acumular capital, independientemente de si tiene o no autorización para hacerlo. Lo anterior representa un riesgo, ya que se trata de trabajos informales o al margen de la legalidad que pueden significar sanciones civiles o despidos sin responsabilidad patronal. Quedaría para otro estudio, de diferente naturaleza, analizar las implicaciones sociales, familiares y psicológicas de permanecer $y$ trabajar ilegalmente, sin la posibilidad de salir y de reingresar a territorio estadounidense y bajo el riesgo de deportación.

Haciendo un análisis más profundo sobre la tenencia de permiso de trabajo según la ocupación, se observa en el cuadro 5, que las mujeres tienen significativamente más autorización para laborar cuando se desempeñan en ocupaciones profesionales y elementales, pero quedan rezagadas en otras categorías. La diferencia es mayor para los puestos de dirección y gerencia, siendo precisamente este rango, el que reporta más ingresos y corresponde a puestos de mando. Esto podría sugerir que las mujeres tendrían una mayor capacidad de hacer un salto cualitativo desde una ocupación elemental hacia una más sofisticada, ya que, en comparación con los hombres, relativamente más mujeres cuentan con autorización laboral para hacerlo.

\section{Estimación de probabilidad de estar empleado}

Como se vio en las estadísticas descriptivas, la gran mayoría de las personas trabaja. Es un resultado esperado que va en concordancia con las estimaciones de Borjas (2017). A continuación, se muestra cuáles son las variables que inciden en esa probabilidad de estar empleado para la población en general, para hombres y mujeres. En el cuadro 6, se presentan los efectos marginales medios de la probabilidad de estar empleado, para mayor facilidad de interpretación. 


\section{RESUMEN DE ESTADÍSTICAS DESCRIPTIVAS PARA HOMBRES Y MUJERES}

\begin{tabular}{|c|c|c|c|}
\hline Variable & $\begin{array}{c}\text { Para la } \\
\text { población en } \\
\text { general }\end{array}$ & Hombres & Mujeres \\
\hline \multirow[t]{2}{*}{ Años de escolaridad } & $-0,0008$ & $-0,0042^{*}$ & $0,0144 * *$ \\
\hline & $(0,0033)$ & $(0,0024)$ & $(0,0066)$ \\
\hline \multirow[t]{2}{*}{ Experiencia } & $0,0181^{* * *}$ & $0,0109 * * *$ & $0,0296^{* * * *}$ \\
\hline & $(0,0036)$ & $(0,0039)$ & $(0,0076)$ \\
\hline \multirow[t]{2}{*}{ Experiencia al cuadrado } & $-0,0003^{* * *}$ & $-0,0002^{* *}$ & $-0,0006^{* * *}$ \\
\hline & $(0,0001)$ & $(0,0001)$ & $(0,0002)$ \\
\hline \multirow[t]{2}{*}{ Permanencia en EEUU } & $-0,0015$ & $-0,0014$ & $-0,0029$ \\
\hline & $(0,0019)$ & $(0,0016)$ & $(0,0035)$ \\
\hline \multirow[t]{2}{*}{ Buen nivel de inglés } & 0,0387 & 0,0431 & $-0,0109$ \\
\hline & $(0,0433)$ & $(0,0537)$ & $(0,0666)$ \\
\hline \multirow[t]{2}{*}{ Si es mujer } & $-0,1129 * * *$ & & \\
\hline & $(0,0315)$ & & \\
\hline \multirow[t]{2}{*}{ Si tiene permiso de trabajo } & 0,0492 & 0,0605 & 0,0307 \\
\hline & $(0,0346)$ & $(0,0385)$ & $(0,0628)$ \\
\hline \multirow[t]{2}{*}{ Red migratoria } & $0,06^{*}$ & 0,0026 & $0,1554 * *$ \\
\hline & $(0,0356)$ & $(0,0276)$ & $(0,0652)$ \\
\hline \multirow[t]{2}{*}{ Personas a cargo } & $-0,0717 * *$ & 0,0218 & $-0,2255^{* * *}$ \\
\hline & $(0,0279)$ & $(0,0258)$ & $(0,0576)$ \\
\hline \multirow[t]{2}{*}{ Si vive en pareja } & $-0,0404$ & $-0,0028$ & $-0,1397 * * *$ \\
\hline & $(0,0274)$ & $(0,0254)$ & $(0,0512)$ \\
\hline \multirow[t]{2}{*}{ Si es jefe de hogar } & 0,0322 & 0,0201 & $-0,0055$ \\
\hline & $(0,0291)$ & $(0,0316)$ & $(0,0492)$ \\
\hline Muestra & 513 & 272 & 241 \\
\hline$X^{2}$ de la estimación original & 61,73 & 27,10 & 35,46 \\
\hline Prob $>X^{2}$ & 0,0000 & 0,0025 & 0,0001 \\
\hline
\end{tabular}

Fuente: : Elaboración propia

Notas: Errores estándar entre paréntesis.

$* \mathrm{p}<0,10, * * \mathrm{p}<0,05, * * * \mathrm{p}<0,01$

Se observa en el cuadro como varios coeficientes son estadísticamente significativos. Además, se encuentra una relación positiva con respecto a la experiencia laboral a una confianza del 99\% para hombres y mujeres y con rendimientos decrecientes. Es importante ver cómo, también a una confianza del 99\%, el ser mujer reduce la probabilidad de estar empleada en un 11,29\%. Aunado a esto, se comprueba que el permiso de trabajo no es significativo en la probabilidad de estar empleado, hipótesis planteada desde el análisis de las estadísticas descriptivas.

Para las mujeres, un año más de escolaridad implica un aumento del 1,44\% en la probabilidad de estar empleada a una significancia estándar del 5\%, un resultado completamente opuesto al que se observa en los hombres, el cual vamos a retomar más adelante. Por otro lado, un año más de experiencia laboral significa para ellas, en promedio, un incremento del 2,96\% en la probabilidad 
de estar empleada, lo cual hace esta variable relativamente más importante para ellas que para los hombres, cuyo impacto es de un 1,09\%. La red migratoria es significativa a un 5\% de significancia $y$, dado su coeficiente asociado, muy importante para las mujeres. Tener acceso a una red migratoria aumenta la probabilidad de estar empleada en un 15,54\% a una significancia estándar del 5\%, variable que no es significativa para el caso de los hombres. Entre los impactos negativos para las mujeres en su probabilidad de estar empleada, se encuentra una reducción de un 22,55\% si tienen personas a cargo y de un 13,97\% si viven con sus parejas. Esta situación es similar a la situación en Costa Rica, donde el número de hijos pequeños incide negativamente en la inserción laboral de las mujeres (Morales \& Segura, 2018).

Dadas las estimaciones anteriores, es claro que la dinámica de empleo es diferente para hombres y mujeres, situación bastante común. Históricamente, a las mujeres se le han delegado labores más domésticas y el cuido de los hijos. Aunque en nuestra población de estudio, la inmensa mayoría de las personas trabajan, y esto se debe a que esta es la razón principal para migrar, las mujeres todavía asumen en gran parte los roles tradicionales domésticos y de crianza de los hijos. Para los hombres, el hecho de vivir en pareja o si tienen personas a cargo no afecta la probabilidad de estar empleado.

Quizás el resultado más inesperado, aunque con una significancia del 10\%, es el signo negativo de los años de educación para los hombres. Un año más de educación significa una reducción de la probabilidad de estar empleado de un $0,41 \%$. Si bien es cierto los resultados resultan atípicos o diferentes a lo que usualmente la teoría del capital humano sugeriría, estos son consistentes con el hecho de que la media de años de escolaridad en personas que no trabajan es alta y esto no pareciera incidir significativamente en el tipo de ocupación desempeñada. En este caso, y tratándose de un país (Estados Unidos) donde la población migrante se dedica mayoritariamente a realizar trabajos más intensivos en mano de obra, pareciera indicar que un hombre con ciertos años de educación formal está menos dispuesto a realizar cualquier tipo de labor, lo que supondría que le cueste más encontrar un empleo adecuado a sus expectativas. La población menos educada, especialmente los hombres, es la más propensa a haber abandonado Costa Rica por situaciones socioeconómicas apremiantes y que, por ende, está dispuesta a realizar cualquier tipo de trabajo manual. Por otra parte, proporcionalmente, más hombres reportaron no estar trabajando por ser estudiantes, esto podría sugerir que, relativamente, más hombres continúan un proceso de educación y esto los aleja de la fuerza laboral. En las mujeres, en cambio, la educación sí es significativa y aumenta la probabilidad de estar empleada, al nivel de confianza estándar.

\section{Estimaciones de ingresos}

En la presente sección se determinará si existe una relación entre el estatus migratorio y los ingresos de la población migrante costarricense. Para establecer esta relación, se toma como referencia el modelo de ingreso de capital humano de Mincer (1974). Las estimaciones están agrupadas por género y por los dos perfiles de ocupaciones que se detallaron en la metodología. Además, el presente análisis se hace incorporando la metodología descrita por Heckman (1979). Lo anterior, por cuanto, el coeficiente asociado que se estimó para la inversa de la razón de Mills, a partir del modelo probit sobre la probabilidad de empleo discutido en la sección anterior, resultó significativo para el caso de los hombres. Así las cosas, se procede a incorporar la variable respectiva para las estimaciones de ingreso atinentes a los hombres.

En el cuadro 7, se presentan los resultados de las estimaciones de ingreso, incluyendo las variables de índole migratorio, de capital humano y de control. 


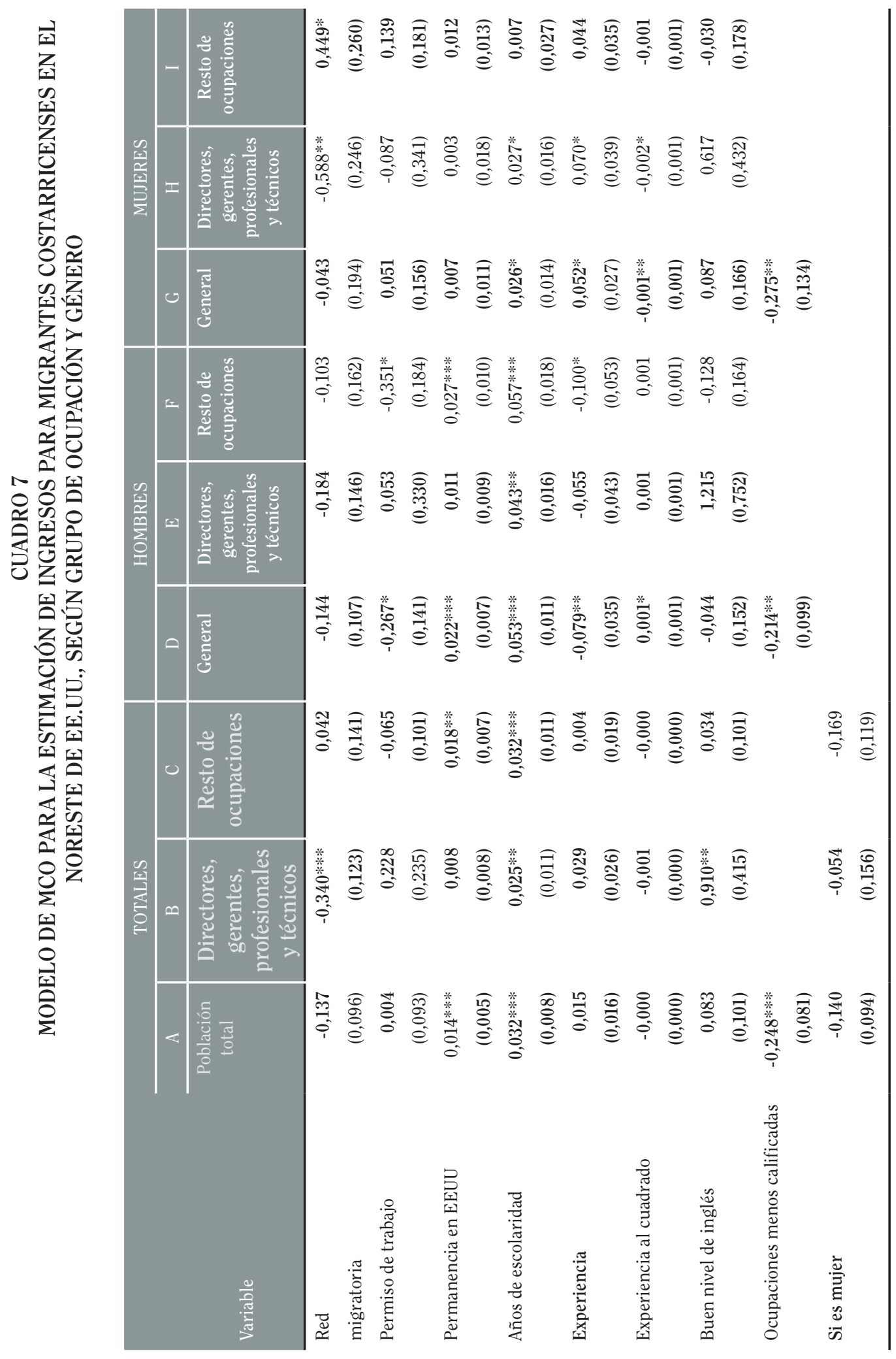




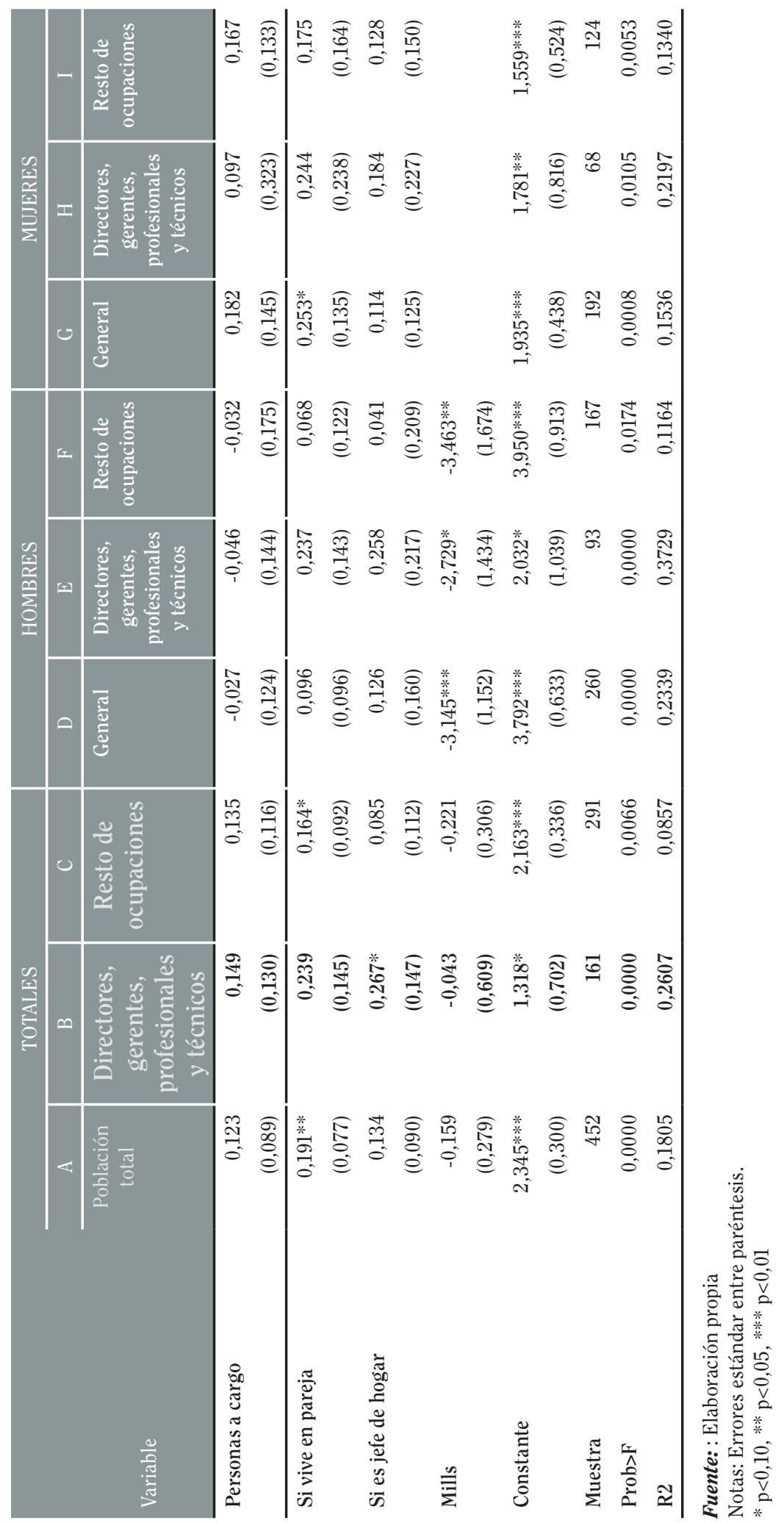

Revista de Ciencias Económicas 38-N¹: enero-junio 2020 / 41-70 / ISSN: 0252-9521 / ISSN: 2215-3489 
Del cuadro anterior se infiere que, si bien es cierto muchos de los coeficientes no son significativos, esto podría deberse a la cantidad de parámetros a estimar relativo a la cantidad de observaciones disponibles. Se puede identificar que las diferencias en el ingreso por género no son significativas; sin embargo, si este modelo se controla únicamente por el género, el ser mujer se asocia negativamente con el ingreso. Esta caída es significativa e importante en todos los casos, donde a un $99 \%$ de confianza, ser mujer representa una disminución en el ingreso de hasta un $23,81 \%$. Para quienes se desempeñan en ocupaciones más elementales, ser mujer representa una caída de hasta un $23,28 \%$ a una significancia estándar del 5\%. Por otro lado, en ocupaciones gerenciales, profesionales, de dirección o técnicas, la brecha salarial por género sería de un 19,74\%, pero a un $10 \%$ de significancia. Estas diferencias serán discutidas en la siguiente sección, para evaluar si hay evidencia de que tales diferencias se deban a diferentes productividades o a un componente no explicado.

De los resultados del cuadro 7 , se infiere que la población migrante costarricense en el noreste de Estados Unidos presenta particularidades importantes, cuando se le estudia mediante el modelo de capital humano usual. Además, se confirma que la variable de la razón inversa de Mills es significativa para el caso de los hombres. Resulta interesante apreciar cómo la experiencia laboral no es significativa para casi ninguno de los casos, entendiendo que la mayoría de las personas que llegan a un nuevo país deben trabajar en lo que esté a su alcance y que no interesa, en muchos casos, la experiencia previa que haya tenido para la determinación de su ingreso. Un resultado inesperado es el signo negativo del coeficiente asociado a la experiencia laboral de los hombres en ocupaciones más elementales, lo cual podría estar asociado al tipo de trabajo a realizar y la edad.

Como se aprecia, la red migratoria se asocia negativamente con el ingreso para aquellas personas que se dedican a profesiones más calificadas a una significancia estándar. El coeficiente asociado a la escolaridad resulta significativo y positivo para el ingreso de los hombres. Para las mujeres, la escolaridad es significativa a un 10\%, si se desempeñan en ocupaciones más calificadas y no es significativa del todo, para las mujeres en ocupaciones más elementales.

Por otro lado, el coeficiente asociado al permiso de trabajo no resulta significativo en la mayoría de los casos. Tal resultado va de la mano con el estudio de Borjas (2017) que, si bien es cierto se trata de una metodología diferente ${ }^{8}$, concluyó que la brecha de ingresos entre migrantes autorizados y no autorizados se ha venido reduciendo en los últimos años. Lo anterior evidencia que tener una autorización para laborar en los Estados Unidos, no significa un aumento en los ingresos de los migrantes. Por el contrario, se obtiene un signo negativo del coeficiente asociado a los hombres con ocupaciones menos sofisticadas. A una significancia del 10\%, la tenencia de permiso de trabajo disminuye su ingreso entre 23,4\% (columna D) y 29,6\% (columna F). Este último dato representa a los hombres que se desempeñan en actividades más elementales. Recordemos que el $42,1 \%$ de los hombres en este tipo de ocupaciones no tiene permiso de trabajo. Sobre el particular, es perfectamente posible pensar que los hombres sin autorización para trabajar se dediquen a trabajos más informales y pagos en efectivo; cuando obtienen autorización para laborar están obligados a pagar impuestos federales y estatales al existir un registro ante la autoridad tributaria (Internal Revenue Services, IRS) y a estar asegurados en la seguridad social de EEUU, lo que disminuye su ingreso disponible en comparación con actividades económicas informales, situación que podría crear incentivos perversos para mantenerse en la informalidad. Por otra parte, saber inglés repercute en un aumento en el ingreso de casi un $150 \%$ para aquellas personas que se desempeñan en ocupaciones con remuneraciones más elevadas (columna B).

La escolaridad sí es significativa y se relaciona positivamente con el ingreso de las personas (excepto para las mujeres en ocupaciones elementales, columna I). En general, para los hombres, un

7 Borjas (2017) desarrolla una metodología de brechas salariales entre migrantes no autorizados y migrantes autorizados, para evaluar la existencia de discriminación contra personas sin documento legal para vivir y trabajar en Estados Unidos. Se encontró que la brecha salarial es pequeña (4\%), la cual se ha venido reduciendo en los últimos años. 
año más de educación implicaría un incremento en el ingreso de 5,3\%. Para las mujeres, esa variable significaría un incremento de 2,6\%, a un 10\% de significancia. En general, se premia relativamente más a los hombres por un año más de escolaridad que a las mujeres.

Se observa una relación negativa entre el ingreso de las personas en ocupaciones más sofisticadas y la red migratoria, particularmente para el caso de las mujeres. Si todo se mantiene constante, una mujer en estas ocupaciones, que tuvo acceso a una red migratoria, tiene una disminución de hasta un 44,45\% en su ingreso a una significancia estándar del 5\%, con respecto a aquellas mujeres en ocupaciones sofisticadas que no contaron con dicha red. Por lo tanto, es posible pensar que los familiares y amigos, tienden a ayudar a colocar a las mujeres en el mercado laboral (la red migratoria es positiva en la probabilidad de estar empleado), pero colocándola en alguna actividad económica afín a su círculo social.

Lo anterior correspondería a un fenómeno económico-social que sugiere que las redes migratorias de parentesco o afinidad personal son beneficiosas para entrar al mercado laboral, pero perjudiciales respecto a los ingresos a mediano y largo plazo. A manera de ejemplo, mediante un caso hipotético, pensemos en una persona que decidió migrar desde Costa Rica, recibiendo ayuda de algún amigo en Estados Unidos. Llega a ese país y encuentra empleo rápidamente en algún círculo social afín a ambos, probablemente en alguna ocupación más elemental. Con el paso del tiempo, cuando esa persona ya logra posicionarse en algún puesto de dirección, gerencial, profesional o técnico, ganará menos que aquella persona que migró desde Costa Rica sin una red migratoria de parentesco o afinidad personal, pero que vino con una visa de trabajo auspiciada por una empresa multinacional o por una visa de estudio en alguna universidad. Esta última persona, aunque no conocía a nadie en el lugar de destino, logra colocarse en el mercado laboral con un mejor ingreso sin necesidad de amigos o familiares, por condiciones completamente diferentes a quienes decidieron salir en busca de mejores condiciones socio económicas. Lo anterior se respalda, incluso, en que quienes dijeron no haber tenido acceso a una red migratoria, reportan una media de ingreso por hora de 36,3 USD, a diferencia de los 26,2 USD en promedio que reportaron los que sí recibieron ayuda para instalarse. Quedaría para otro estudio analizar el impacto de otros tipos de redes migratorias de más alto nivel, como las becas universitarias o traslados horizontales en multinacionales.

Ahora bien, en cuanto a la diferencia en el ingreso entre alguien que se desempeñe en una ocupación más sofisticada en comparación con una más elemental, si todo se mantiene constante, tenemos que para los hombres la disminución significaría hasta un 19,2\% y un 24,04\% para las mujeres, ambos resultados a una significancia estándar del 5\%.

\section{Modelo de brechas de ingreso por género y discriminación}

En la sección anterior, se encontró una brecha en el ingreso, cuando se estiman los ingresos de las personas, si se controla el modelo únicamente por la variable de género. Tal brecha desaparece cuando controlamos el modelo con las demás variables sociodemográficas.

En la presente sección, se evalúan las estimaciones subdividiendo las variables en variables de índole migratorio, variables de capital humano y variables de control. Mediante la metodología de Oaxaca y Ransom (1994), se determinará si existe una diferencia significativa en el ingreso de hombres y mujeres $y$ si esa diferencia se da como resultado de productividades diferentes (diferencia explicada; o si, por el contrario, se debe a un componente no explicado. Como el cálculo del ingreso sugiere que es necesario hacer una corrección de Heckman (1979) para los hombres, se procede a calcular los modelos tomando en cuenta la variable de la razón inversa de Mills calculada para los hombres.

En el cuadro 8, se presentan los resultados, independientemente de la ocupación de la persona, para directores, gerentes, profesionales y técnicos $y$, por último, para el resto de las ocupaciones. Todos los resultados fueron ajustados con el modelo de Heckman para los hombres. 


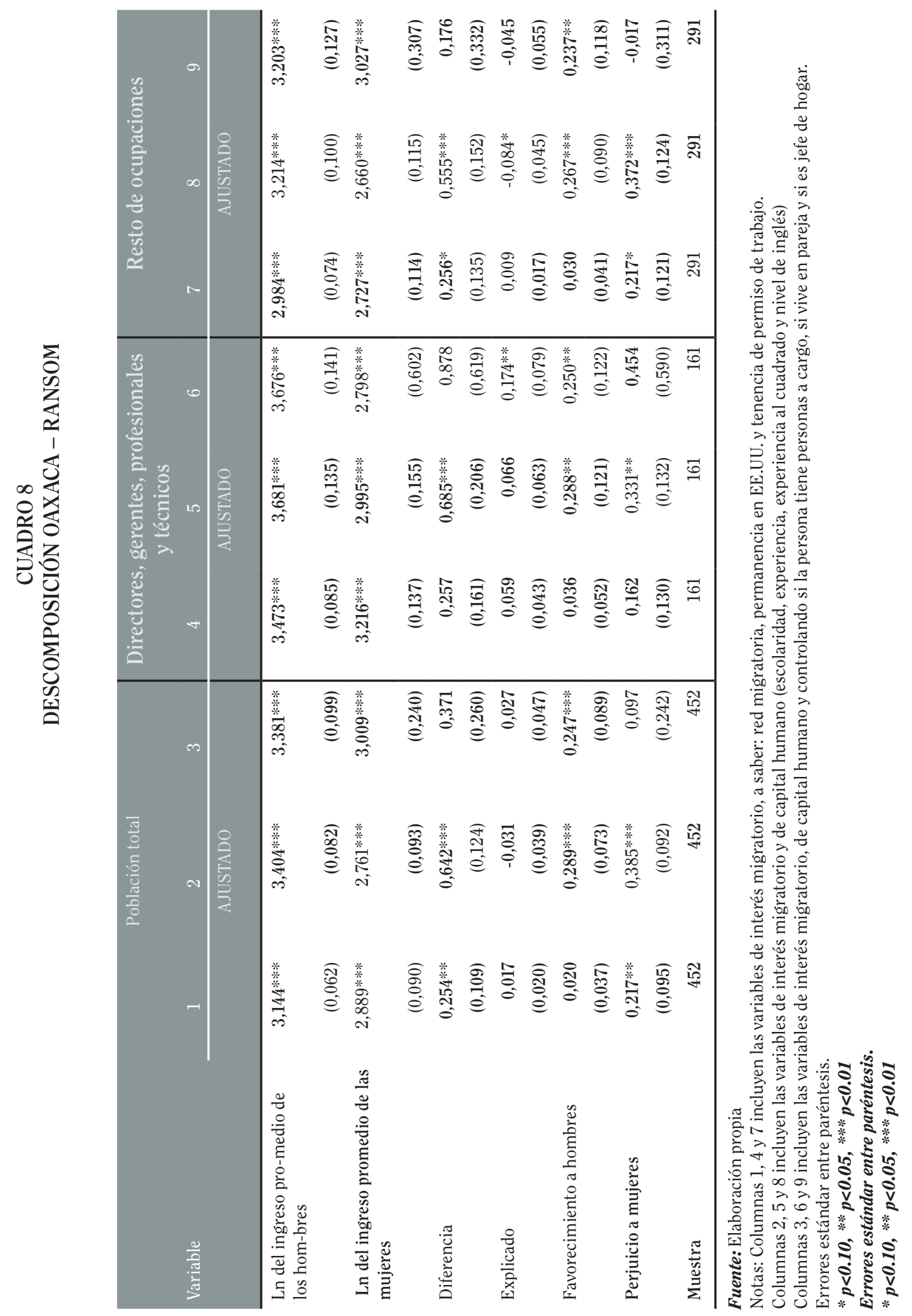


Considerando los resultados del modelo ajustado, y similar a lo encontrado en la sección anterior, resulta interesante ver que las diferencias dejan de ser significativas cuando se le agregan variables de control (columnas 3,6 y 9); sin embargo, con el modelo con variables de interés y de capital humano, las diferencias son significativas a un 99\% de confianza, presentando una diferencia no explicada, que sugeriría la presencia de discriminación. Mediante la metodología de OaxacaRansom (1994) es posible desagregar ese componente no explicado en dos efectos: el primero es el favorecimiento por parte de los empleadores a los hombres y el segundo, el perjuicio a las mujeres. Estos dos componentes desagregados son significativos, tanto para la población en general, como para los dos perfiles de ocupaciones que se detallaron en la metodología. Como se desprende del cuadro 8, el porcentaje de perjuicio a las mujeres es más grande que el favorecimiento a los hombres en todos los casos.

Solamente para el caso de las ocupaciones más elementales, una proporción $(15,13 \%)$ de esa diferencia está explicada por la diferencia en la productividad. Cabe resaltar que este componente explicado es negativo y significativo a un $90 \%$ de confianza, lo cual significa que, en las ocupaciones más elementales, las mujeres poseen una mejor dotación de capital humano y productividad que repercute positivamente en sus ingresos; sin embargo, en estas ocupaciones, el efecto de discriminación es tan alto, que no solo anula el efecto positivo de una mejor productividad de las mujeres, si no que va más allá, dejando sus ingresos muy por debajo del ingreso de los hombres.

En relación con los componentes no explicados que resultaron significativos al incluir variables de capital humano, el componente no explicado de perjuicio a las mujeres y favorecimiento a los hombres son significativos al 1\% de significancia y con coeficientes muy altos. Para la población en general y para ocupaciones elementales, ese componente no explicado supera el monto total de la diferencia en el ingreso, al tener el componente explicado un signo negativo. Para quienes se desempeñan en ocupaciones más sofisticadas, ese porcentaje es del 90\%. Dicho de otra manera, las diferencias en el ingreso entre hombres y mujeres no se deben a una diferencia en la productividad de las personas. Es decir, las mujeres estarían igual o incluso mejor calificadas, pero se les paga menos. Lo anterior es consistente considerando que la brecha salarial entre hombres y mujeres en Estados Unidos es una realidad y que Nueva Jersey, Estado con más del 50\% de los costarricenses radicados en esta región del país, presenta la mayor brecha salarial entre latinas y hombres blancos de todo Estados Unidos (National Partnership for Women and Families, 2017).

Cuando se agregan variables de interés, si bien es cierto se obtiene que la diferencia no es significativa, el modelo arroja indicios de que existe un favorecimiento por parte de los empleadores a los hombres, lo que también correspondería a discriminación, al nivel de confianza estándar.

\section{CONCLUSIONES}

Con la presente investigación se logró formular y recopilar, por primera vez, una base de datos con información valiosa acerca del perfil demográfico, de los ingresos y tenencia de permiso laboral de la población migrante costarricense en el noreste de Estados Unidos. Se trata de un primer acercamiento, desde una oficina consular, para recabar información y abordar el tema migratorio desde una perspectiva de economía laboral.

Se determinó que el ingreso de los migrantes está determinado por ciertas variables de índole migratorio como la tenencia de permiso de trabajo, el acceso a capital social de amigos y familiares a la llegada a los Estados Unidos (red migratoria), y los años de residencia en este país; por variables usuales del modelo de capital humano, como la escolaridad, experiencia y el dominio del inglés; $y$ por variables de control de características personales. Sin embargo, la investigación evidencia que estudiar esta población con modelos tradicionales de capital humano es complejo, ya que existen variables no cuantificables que afectan las decisiones y el ingreso de las personas. 
Ahora sabemos que un 32\% de la muestra no cuenta con autorización para laborar: un 33,5\% de los hombres y un 29,5\% de las mujeres. Además, se lograron identificar dos perfiles poblacionales diferentes. El primero corresponde a aquellas personas que migraron desde Costa Rica por una buena oportunidad laboral, estudio o capacitación técnica, quienes a menudo cuentan y siempre contaron con un estatus legal para laborar o estudiar en ese país. Estas personas provienen en mayor proporción del Gran Área Metropolitana de San José, Costa Rica y se asientan relativamente más en los Estados de Nueva York y Massachusetts. El segundo perfil corresponde a personas que no contaban con estas oportunidades y decidieron salir de Costa Rica por necesidades socio económicas apremiantes, ingresando de manera irregular a Estados Unidos o quedándose más tiempo del permitido inicialmente. Provienen, en mayor proporción que el otro grupo, de los cantones de Pérez Zeledón, Buenos Aires y la Zona de los Santos.

Con el objetivo de estudiar el ingreso de estos dos perfiles poblacionales, se determinaron dos grupos ocupacionales diferentes: el primero con aquellas personas en puestos gerenciales, de dirección, profesionales y técnicos; y el segundo con aquellas personas en ocupaciones más elementales. Se determinó que el primer grupo reporta más ingresos, mayor proporción de personas con permiso de trabajo y menor proporción de personas que recibieron ayuda de una red migratoria de familiares o amigos; en contraste con los ocupados en el segundo grupo. En el grupo de ocupaciones más sofisticadas, más hombres ostentan puestos de dirección y gerenciales. En contraparte, más mujeres tienen puestos como profesionales. Dicha situación perjudica mayoritariamente a las mujeres, ya que los puestos de dirección y gerencia son los que mayores ingresos reportan.

En el proceso de determinar qué afecta el empleo de las personas, se logró confirmar que la gran mayoría de personas tienen trabajo. Destaca el $80 \%$ de participación femenina en el mercado laboral en Estados Unidos, muy superior al 50\% en Costa Rica (Morales \& Segura, 2018), reafirmando que la búsqueda de nuevas oportunidades de empleo es el motivo principal para migrar. Por otra parte, aquellos con más años de escolaridad ven aumentada su probabilidad de estar empleados; sin embargo, en general, las mujeres tienen un 11,29\% menos probabilidad de trabajar que un hombre. Más mujeres asumen roles tradicionales que les han sido asociados: cuido de niños y atención al hogar. La presencia de personas a su cuido representa una disminución en su probabilidad de trabajar de hasta un 22,54\%. Esta situación es similar a la situación en Costa Rica, donde el número de hijos pequeños incide negativamente en la inserción laboral de las mujeres (Morales \& Segura, 2018). Por otro lado, el acceso a una red migratoria hace que las mujeres vean aumentada esa probabilidad hasta en un $15,5 \%$. Todos los resultados anteriores se obtuvieron a un grado de significancia estándar.

En relación con el impacto de la tenencia de autorización para laborar en el ingreso de las personas, este no es significativo. Más bien, la tenencia de permiso de trabajo repercute negativamente, hasta en un 29\%, sobre el ingreso de los hombres que se dedican a ocupaciones más elementales a un nivel de significancia del 10\%. Tales resultados inesperados se explicarían debido a que, una vez que los migrantes regularizan su situación migratoria, entran formalmente al mercado laboral de los Estados Unidos, sin posibilidad de evadir el pago de las cargas sociales e impuestos correspondientes.

El hecho de que en otros grupos el permiso para trabajar haya resultado no significativo, no quiere decir que el tener una autorización legal no sea importante para el desarrollo y la estabilidad personal y familiar de los migrantes. A manera de ejemplo, a inicios de 2017, muchas personas dejaron de asistir al Consulado en Nueva York a realizar sus trámites, por miedo a redadas inesperadas que habían sido anunciadas por la nueva administración. Además, existe un fenómeno social y psicológico al no tener la libertad de salir y reingresar a los Estados Unidos, como sí lo pueden hacer los migrantes autorizados. 
Otra variable con resultado interesante es la presencia de redes migratorias, las cuales están significativamente relacionadas con el ingreso de las mujeres, pero con signos contrarios: positivas y con una significancia del $10 \%$ para aquellas que se dedican a ocupaciones más elementales, cuyas ocupaciones más usuales son las trabajadoras en el sector servicios y limpieza de casas y oficinas; $y$ negativas con un nivel de confianza estándar, para aquellas mujeres que se desempeñan en ocupaciones más sofisticadas. Esto podría deberse a que, si bien es cierto la red migratoria ayuda a abrir la puerta del empleo en los Estados Unidos, es razonable pensar que amigos y familiares colocarán a sus allegados en un círculo social afín y en labores comunes. Contrario a quien llega sin una red migratoria, por ejemplo, transferido a alguna compañía o como futuro profesional que llega como estudiante a una universidad.

En cuanto a las brechas en el ingreso con respecto al género, se hicieron las estimaciones respectivas y se encuentra que, en aquellos modelos donde se utilizan las variables de interés migratorio y de capital humano, hay evidencia estadística para decir que existe una brecha en el ingreso. A un nivel de significancia estándar, las mujeres ganan en promedio un 23,8\% menos ingreso que los hombres, siendo la brecha levemente menor y significativa a un $10 \%$, si se trata de ocupaciones más sofisticadas. Sin embargo, esa diferencia en el ingreso deja de ser significativa cuando se agregan variables de control. Estas brechas son mayores a las reportadas en Costa Rica, correspondiente a un 12\% de los ingresos para el año 2017 (Informe del Estado de la Nación, 2018).

Al tratar de explicar la brecha salarial por género encontrada en los modelos con variables migratorias y de capital humano, se reitera que hay una diferencia salarial no explicada y significativa a un nivel de confianza estándar, que está afectando a las mujeres en general y según su perfil ocupacional. Además, a los hombres se les premia más por un año más de escolaridad que a las mujeres, aunque sean ellas más escolarizadas. Particularmente, se vio cómo la escolaridad no es significativa en el ingreso de las mujeres que se dedican a ocupaciones más elementales. Agregando las variables de control, aunque no se encontró una diferencia en el ingreso significativa, el modelo sugiere que hay un componente discriminatorio manifestado como un favorecimiento a los hombres.

El estudio también expuso ciertas limitaciones, como la representatividad de la muestra. No es posible afirmar fehacientemente que la muestra es representativa de la población migrante costarricense en general, ya que su construcción se basó en la visitación de los migrantes al Consulado. Si bien es cierto, se expuso que la mayoría de las personas deben visitar el Consulado con alguna frecuencia, no se puede afirmar con absoluta contundencia que representa a una población total.

Otra limitación encontrada está relacionada con la definición de red migratoria, ya que se abordó el tema desde una red de parentescos, de afinidad personal o de círculo social afín. La investigación permitió encontrar que existen otras redes, académicas y laborales, que coadyuvan a la migración. Tal es el caso de personas costarricenses que llegan a Estados Unidos transferidas desde Costa Rica por medio de una empresa multinacional o una universidad. Quedaría para investigaciones futuras, estimar el efecto en el ingreso de las personas que tienen acceso a este tipo de redes y el impacto para Costa Rica y la relación que tiene esta migración con la inversión extranjera directa.

Además, la investigación se limitó a medir el impacto en el ingreso de la tenencia o no de permiso de trabajo, pero no se abordó el efecto que tiene el riesgo de deportación en la tenencia o no de permiso de trabajo. Tampoco se ahonda en los efectos personales, sociales y psicológicos sobre la incertidumbre de no tener permiso de trabajo, la imposibilidad de visitar su país de origen y el riesgo de deportación.

La expectativa es que estas conclusiones y hallazgos sirvan como herramienta de trabajo a las autoridades pertinentes. Por ejemplo, se podrían reorientar los escasos recursos en generar conciencia de la importancia, independientemente del impacto en los ingresos, de la tenencia de permiso de trabajo. En el tema de género podría promoverse que, mediante asociaciones sin fines 
de lucro o capacitación técnica desde Costa Rica, las mujeres den un salto cualitativo a ocupaciones más sofisticadas, donde su preparación sí se traduce a mejores ingresos. Otras acciones podrían estar orientadas en difundir las acciones realizadas por el Consulado o dotar al Consulado de recursos para retomar la visitación del personal a comunidades con concentración de costarricenses. Esto colaboraría a paliar la queja constante de los migrantes sobre el olvido por parte de las autoridades nacionales.

Por el momento, se cumplió con el compromiso inicial de compartir la base de datos y los resultados con el Consulado, constituyendo el primer aporte de esta índole para una oficina en el exterior. Se espera que los hallazgos sean elevados a la Dirección General del Servicio Exterior de Costa Rica del Ministerio de Relaciones Exteriores y a la Dirección General de Migración. Conocer mejor a la población migrante y comprender sus necesidades, permite encausar potenciales iniciativas de política económica para que se prioricen los recursos limitados a los sectores más vulnerables.

\section{AGRADECIMIENTOS}

A todas las personas que amablemente respondieron el cuestionario y a la PhD. Laura Blanco, profesora de la escuela de Economía de la Universidad de Costa Rica, por sus invaluables aportes.

\section{REFERENCIAS}

Aptekar, S. (2015). The road to citizenship. What naturalization means for immigrants and the United States. Nueva Jersey: Rutgers University Press.

Becker, G. (1962). Investment in Human Capital: A Theoretical Analysis. Journal of Political Economy, 70(5), 9-49. JSTOR.

Borjas, G (2017, marzo). The Earnings of Undocumented Immigrants (Harvard Kennedy School Faculty Research Working Paper Series RWP17-013).

Boswell, C. (2002). Addressing the causes of migratory and refugee movements: the role of the European Union. (Institute for Peace Research and Security Policy Working Paper No. 73).)

Caamaño, C. (2010). La experiencia transnacional de la migración de costarricenses hacia Estados Unidos. San José, Costa Rica: Editorial UCR.

Caicedo, M. (2015). La desigualdad salarial entre inmigrantes latinoamericanos y nativos en Estados Unidos (1980-2010). Norteamérica, 10(1), 133-164. https://doi.org/10.20999/nam.2015.a005

Capps, R., Bachmeier, J., Fix, M., Van-Hook, J. (2013). A demographic, socioeconomic and health coverage profile of unauthorized immigrants in the Unites States. (Migration Policy Institute Issue Brief $\mathrm{N}^{\circ}$ 5). https://www.migrationpolicy.org/research/demographic-socioeconomic-andhealth-coverage-profile-unauthorized-immigrants-united-states

Capps, R., Fix, M. \& Zong, J. (2016, junio). A profile of US children with unauthorized immigrant parents. (Migration Policy Institute, Fact Sheets). https://www.migrationpolicy.org/research/ profile-us-children-unauthorized-immigrant-parents.

Cedeño, J., González, A. \& Pizarro, K. (2015). Discriminación salarial por género en Costa Rica durante los ciclos económicos del período 1992-2013. (Tesis para optar por grado de Licenciatura), Universidad de Costa Rica, San José. http://hdl.handle.net/10669/29982

Consulado General de Costa Rica en Nueva York (2017). Sistema de Gestión Consular. Ministerio de Relaciones Exteriores, San José: Departamento Consular

Ennis, S. R., Ríos-Vargas, M., \& Albert, N. G. (2011). The Hispanic Population: 2010. (United States Census Bureau, Report Number C2010BR-04). https://www.census.gov/library/ publications/2011/dec/c2010br-04.html 
Guilford, G. (2017, 29 de marzo). Unauthorized workers in the US now earn almost as much as those who work legally. Revista Económica Qwartz. Recuperado el 19 de octubre de 2017, de https:// qz.com/939526/things-have-been-getting-better-for-americas-unauthorized-immigrants/

Heckman, J. J. (1976). The Common structure of statistical models truncation, sample selection and limited dependent variables and a simple estimator for such models. Annals of Economic and Social Measurement, 5(4), 475-492. https://www.nber.org/chapters/c10491

Heckman, J. J. (1979). Sample Selection Bias as a Specification Error. Econometrica, 47(1), 153-161. https://doi.org/10.2307/1912352

Instituto Nacional de Estadística y Censos (2014). Clasificación de ocupaciones de Costa Rica. Recuperado el 4 de abril de 2019 de https:/www.inec.cr/documento/inec-2011-clasificacion-deocupaciones-de-costa-rica-ciiuo-08-manual-de-ocupaciones-marzo

Instituto Nacional de Estadística y Censos (2014). Costa Rica a la luz del Censo del 2011. Instituto Nacional de Estadística y Censos. Recuperado el 19 de octubre de 2017 de https://www.inec.cr/ documento/censo-2011-simposiocosta-rica-la-luz-del-censo-2011

Lara Lara, J. (2017). Ingresos laborales en México y Estados Unidos para migrantes temporales. Migraciones internacionales, 9(1), 95-117. SCIELO

Kordick-Rothe, C. (2007). "Primeros emigrantes de Costa Rica a Nueva York y Nueva Jersey". En Sandoval, C. (comp.). El mito roto. Instituto de Investigaciones Sociales, Universidad de Costa Rica, pp. 177-192.

Massey, D. S., \& García-España, F. (1987). The Social Process of International Migration. Science, 237(4816), 733-738. JSTOR.

Min Kim, S., Bahrampour, T. \& Wagner, J. (2019, 11 de julio). Trump retreats on adding citizenship question to 2020 Census. Washington Post. Recuperado el 30 de enero de 2020 de https:// www.washingtonpost.com/politics/trump-to-hold-news-conference-on-census-as-he-mullsexecutive-action-to-add-a-citizenship-question/2019/07/11/c0eb7cb6-a3c8-11e9-b8c875dae2607e60_story.html

Mincer, J. (1974). Schooling, Experience and Earnings. National Bureau of Economic Research.

Ministerio de Relaciones Exteriores (2001). Reglamento al Estatuto del Servicios Exterior de la República No. 29428-RE. Ministerio de Relaciones Exteriores, Decreto Ejecutivo Poder Ejecutivo de Costa Rica. Recuperado el 30 de noviembre de 2017 de http:/www.pgrweb.go.cr/ scij/Busqueda/Normativa/Normas/nrm_texto_completo.aspx

Morales, N. \& Segura, R. (2018). Barreras de acceso al mercado laboral y predicción de movilidad laboral entre sectores económicos con enfoque de género. San José, Costa Rica: Informe del Estado de la Nación. http://hdl.handle.net/20.500.12337/2972

National Partneship for Women and Families (2017). Latinas and the Wage Gap. (National Partneship for Women and Families, Fact Sheet). Recuperado el 24 de agosto de 2017 de http://www. nationalpartnership.org/research-library/workplace-fairness/fair-pay/latinas-wage-gap.pdf

National Women's Law Center (2017a). Frequent Asked Questions about the wage gap. (National Women's Law Center, Fact Sheet). Recuperado el 4 de octubre de 2017 de https://nwlc.org/ wp-content/uploads/2017/09/FAQ-About-the-Wage-Gap-2017.pdf

National Women's Law Center (2017b). The wage gap by state for latinas. (National Women's Law Center, Fact Sheet). Recuperado el 4 de octubre de 2017, de https://nwlc.org/resources/wagegap-state-latinas/

Oaxaca, R. L., \& Ransom, M. R. (1994). On discrimination and the decomposition of wage differentials. Journal of Econometrics, 61(1), 5-21. https://doi.org/10.1016/03044076(94)90074-4 
Organización Internacional del Trabajo (2017). Labour migration in Latin America and the Caribbean. Diagnosis, Strategy and ILO's work in the Region. (ILO Technical Reports, 2016/2). Recuperado el 18 de octubre de 2017 de http://www.ilo.org/americas/publicaciones/ WCMS_548185/lang--en/index.htm

Organización Internacional para las Migraciones (2015). Mapa interactivo de migraciones. Recuperado el 20 de octubre de 2017 de https://www.iom.int/world-migration

Solórzano, A (2018). Discriminación salarial por motivo de género en Costa Rica. (Ponencia presentada como investigación base para el Informe Estado de la Nación en Desarrollo Humano Sostenible, no. 24). http://hdl.handle.net/20.500.12337/2971

Tribunal Supremo de Elecciones (2013). Reglamento para el Ejercicio del Voto en el Exterior. Recuperado el 30 de octubre de 2017 de https://www.tse.go.cr/pdf/normativa/ reglamentoparaelejerciciodelvotoenelextranjero.pdf

U.S. Census Bureau (2018). American Community Survey 2018. Selected population profiles y Public Use Microdata. Recuperados el 3 de junio de 2020 de https://data.census.gov/cedsci/

Unites States Department of Homeland Security (2018). Estimates of the Unauthorized Immigrant Population Residing in the United States. Recuperado el 30 de enero de 2020 de https://www. dhs.gov/immigration-statistics/population-estimates/unauthorized-resident 